Check for updates

Cite this: RSC Adv., 2017, 7, 46069

\section{Adding a solvophilic comonomer to the polymerization-induced self-assembly of block copolymer and homopolymer: a cooperative strategy for preparing large compound vesicles $\uparrow$}

\author{
Chundong Huang, ${ }^{a}$ Jianbo Tan, (D *ab $Q i n ~ X u,{ }^{a}$ Jun He, ${ }^{a}$ Xueliang Li, ${ }^{a}$ Dongdong Liu ${ }^{a}$ \\ and Li Zhang*ab
}

\begin{abstract}
We report a reversible addition-fragmentation chain transfer (RAFT) dispersion polymerization of styrene (St) and 4-vinylpyridine (4VP) in methanol/water at $70{ }^{\circ} \mathrm{C}$. The polymerization was mediated by a binary mixture of S-1-dodecyl-S'-( $\alpha, \alpha^{\prime}$-dimethyl- $\alpha^{\prime \prime}$-acetic acid) trithiocarbonate (DDMAT) and monomethoxy poly(ethylene glycol)-based macromolecular RAFT agent (mPEG 45 -DDMAT). By varying the molar ratio of $[\mathrm{St}]_{0} /[4 \mathrm{VP}]_{0}$, polymer nano-objects of different morphologies (porous vesicles, large compound vesicles (LCVs), and lamellae) were formed. Transmission electron microscopy (TEM) observations demonstrated that LCVs were formed by further aggregation and reorganization of vesicles during the process. Effects of [mPEG ${ }_{45}$-DDMAT]/[DDMAT] molar ratio, methanol/water ratio, and degree of polymerization (DP) of the core-forming block on the assemblies were also studied in detail. Ag(amPEG ${ }_{45}-P\left(\mathrm{St}_{108}-\mathrm{CO}-4 \mathrm{VP}_{24}\right) /$ $\mathrm{P}\left(\mathrm{St}_{108}-\mathrm{CO}-4 \mathrm{VP}_{24}\right) \mathrm{LCVs}$ were prepared by in situ reduction of $\mathrm{AgNO}_{3}$, as confirmed by TEM and UV-vis measurements. The obtained Ag(amPEG ${ }_{45}-\mathrm{P}\left(\mathrm{St}_{108}-\mathrm{CO}-4 \mathrm{VP}_{24}\right) / \mathrm{P}\left(\mathrm{St}_{108}-\mathrm{CO}-4 \mathrm{VP}_{24}\right) \mathrm{LCVs}$ exhibited catalytic activity for the catalysis of methylene blue (MB) using $\mathrm{NaBH}_{4}$.
\end{abstract}

Received 17th August 2017 Accepted 20th September 2017

DOI: 10.1039/c7ra09120f

rsc.li/rsc-advances and RAFT-mediated dispersion polymerization. The former one requires the use of water insoluble monomers and the majority of RAFT aqueous emulsion polymerization formulations reported in the literature only lead to kinetically-trapped spheres. ${ }^{20-24}$ In the latter case, monomers are soluble in the reaction mixture while the resulted polymers are insoluble. A diverse set of morphologies (e.g. spheres, worms, and vesicles) have been prepared by RAFT-mediated dispersion polymerization in water, ${ }^{25-30}$ alcohols, ${ }^{31-47}$ non-polar solvents, ${ }^{48-50}$ and even poly(ethylene glycol), ${ }^{51}$ demonstrating the versatility of this method. Very recently, photoinitiated polymerization-induced selfassembly (photo-PISA) developed by our group and others enables environmental-responsive and bio-related polymer nanoobjects to be prepared at room temperature..$^{52-62}$ Oxygen-tolerant photo-PISA formulations have also been developed in the presence of enzyme and singlet oxygen quenchers. ${ }^{63,64}$

Although various block copolymer nano-objects have been prepared by PISA, the morphologies are typically limited to spheres, worms, and vesicles. To address this problem, the synthesis of blends of block copolymers (including $\mathrm{BAB} / \mathrm{AB}, \mathrm{AB} /$ B) via PISA has recently been explored to control the morphology of polymer nano-objects. For example, Gao et al. ${ }^{46}$ reported the in situ synthesis of self-assembled blends of $\mathrm{BAB} /$ $\mathrm{AB}$ block copolymers via two macro-RAFT agents comediated dispersion polymerization. Porous vesicles and nanospheres have been prepared by this strategy. Most recently, in situ
${ }^{a}$ Department of Polymeric Materials and Engineering, School of Materials and Energy, Guangdong University of Technology, Guangzhou 510006, China. E-mail: tanjianbo@ gdut.edu.cn; lizhang@gdut.edu.cn

${ }^{b}$ Guangdong Provincial Key Laboratory of Functional Soft Condensed Matter, Guangzhou 510006, China

$\dagger$ Electronic supplementary information (ESI) available: The measurement of monomer conversion and additional results. See DOI: 10.1039/c7ra09120f 
synthesis of polymer nano-objects consist of diblock copolymer and homopolymer has been developed by our group and others by adding a small amount of small molecular RAFT agent into PISA. It was found that the presence of homopolymer promoted the formation of higher order morphologies, e.g. porous vesicles were formed in the case of PISA of St when using a $\mathrm{mPEG}_{45^{-}}$ DDMAT macro-CTA. ${ }^{34,65,66}$ Another strategy to prepare complex polymer nano-objects is seeded dispersion polymerization. For example, Shi et $a .^{47}$ synthesized redox-responsive multicompartment vesicles via seeded dispersion polymerization of ferrocene-containing triblock terpolymers. The obtained vesicles exhibited on-off switchable pores via redox triggering. He et $a l .{ }^{67}$ reported the preparation of multicompartment nanoparticles of poly( $N, N$-dimethylacrylamide)- $b$-polystyrene- $b$ poly(4-vinylpyridine) (PDMA- $b$-PS- $b$-P4VP) triblock terpolymer. The size of P4VP domains increased with the degree of polymerization (DP) of P4VP.

In the study, we report a facile PISA formulation in the presence of a small molecular RAFT agent and a solvophilic comonomer for the preparation of novel morphologies that has never been reported before. Adding small molecular RAFT agent into PISA leads to in situ formation of blends of block copolymer and homopolymer and thus increasing the volume fraction of solvophobic block as addressed above. On the other hand, the incorporation of solvophilic comonomer increases the solvophilicity of homopolymer, and thus drawing the homopolymer from the inner of vesicle membrane to the surface to form domains. As the polymerization proceeds, the size of homopolymer domains without stabilization increases. To lower the interfacial energy inside and within vesicles, vesicles collapse and aggregate to form LCVs. It should be noted that adding solvophilic monomers into typical PISA of diblock copolymers only facilitates the formation of lower order morphologies. For example, Shi et al. ${ }^{68}$ reported that the morphology changed from vesicles to lamellae to worms and finally spheres with increasing the amount of $4 \mathrm{VP}$ in PISA of mPEG $_{45}$-PSt, which was attributed to the decreasing packing parameter of the diblock copolymers. Therefore, the present cooperative strategy will further expand the scope of PISA and provide a new platform for the synthesis of complex and interesting morphologies. Moreover, the incorporation of solvophilic monomer into the coreforming block enables the introduction of functional groups, thus allowing the preparation of functional polymer nanoobjects (e.g. inorganic/organic composite).

\section{Experimental section}

\section{Materials}

Styrene (St, Aladdin) and 4-vinylpyridine (4VP, Aladdin) were purified by passing through a basic alumina oxide (Aladdin) column prior to storage at $4{ }^{\circ} \mathrm{C}$. Monomethoxy poly(ethylene glycol) $\left(\mathrm{mPEG}_{45}, 2000 \mathrm{~g} \mathrm{~mol}^{-1}\right.$, Sigma-Aldrich), dicyclohexylcarbodiimide (DCC, Aladdin), 4-dimethylaminopyridine (DMAP, Aladdin), silver nitrate $\left(\mathrm{AgNO}_{3}\right.$, Aladdin), sodium borohydride $\left(\mathrm{NaBH}_{4}\right.$, Aladdin), methylene blue (MB, Aladdin), and hydroquinone (Aladdin) were used without further purification. 2,2-Azobisisobutyronitrile (AIBN, Aladdin) was recrystallized from ethanol prior to storage under refrigeration at $4{ }^{\circ} \mathrm{C}$. S-1-dodecyl-S'-( $\alpha, \alpha^{\prime}$-dimethyl- $\alpha^{\prime \prime}$-acetic acid) trithiocarbonate (DDMAT) was synthesized according to a published procedure. $^{69}$

\section{Characterization}

Transmission electron microscope (TEM). The polymerization reaction mixtures were diluted 100 -fold with methanolwater mixtures. A drop of the solution was placed on the copper grid for $1 \mathrm{~min}$ and then blotted with filter paper to remove excess solution. TEM observations were carried out on a JEM1400PLUS instrument operated at $120 \mathrm{kV}$.

Scanning electron microcopy (SEM). SEM images were collected using a Hitachi S4800 electron microscope on samples sputter-coated with gold prior imaging. The samples for SEM imaging were prepared by drop casting the diluted dispersion on mica films and drying at ambient temperature prior to sputter-coating.

Gel permeation chromatography (GPC). The molar mass and polydispersity of polymers were measured by GPC at $35^{\circ} \mathrm{C}$ using a Waters 1515 GPC instrument with tetrahydrofuran (THF) as the mobile phase and Waters styragel HR1, HR4 columns. The flow rate of THF was $1.0 \mathrm{~mL} \mathrm{~min}^{-1}$. Linear polystyrene polymers with narrow molar mass distributions were used as the standards to calibrate the apparatus.

${ }^{1}$ H NMR spectroscopy. ${ }^{1} \mathrm{H}$ NMR spectra were recorded in $\mathrm{CDCl}_{3}$ using a Bruker Avance III $400 \mathrm{MHz}$ NMR spectrometer at a temperature of $25^{\circ} \mathrm{C}$. Note: the samples prepared by PISA were first diluted with methanol and then dissolved in $\mathrm{CDCl}_{3}$.

UV-vis spectroscopy. UV-vis spectra were recorded with a $1.0 \mathrm{~cm}$ quartz cuvette using a UV2450 spectrometer.

\section{Synthesis of mPEG $_{45}$-DDMAT}

A solution of DDMAT $(7.29 \mathrm{~g}, 20 \mathrm{mmol})$ in $40 \mathrm{~mL}$ of anhydrous dichloromethane (DCM) was introduced in a dry flask under nitrogen atmosphere containing mPEG$_{45}(20.0 \mathrm{~g}, 10 \mathrm{mmol})$. Then a solution of DCC $(4.12 \mathrm{~g}, 20 \mathrm{mmol})$ and DMAP $(0.244 \mathrm{~g}$, $2 \mathrm{mmol}$ ) in $10 \mathrm{~mL}$ of anhydrous DCM was added dropwise to the reaction mixture at $0{ }^{\circ} \mathrm{C}$. The esterification reaction proceeded under stirring at room temperature for $48 \mathrm{~h}$. The polymer was collected by precipitation of the reaction mixture in hexane, passing through a silica column, and finally dried at $45{ }^{\circ} \mathrm{C}$ under vacuum to obtain a yellow powder.

\section{RAFT dispersion polymerization}

In a typical experiment ([mPEG $\left.45^{-D D M A T}\right] /[\mathrm{DDMAT}]=1 / 1$, $[\mathrm{St}]_{0} /[4 \mathrm{VP}]_{0}=4 / 1$, target degree of polymerization (DP) of 200 , monomer concentration $(\mathrm{St} / 4 \mathrm{VP})$ of $15 \% \mathrm{w} / \mathrm{w}$ : St $(1.20 \mathrm{~g}$,

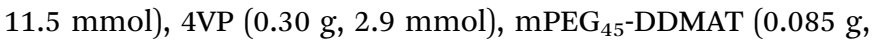
$0.036 \mathrm{mmol})$, DDMAT (0.013 g, $0.036 \mathrm{mmol})$, AIBN (0.0039 g, $0.024 \mathrm{mmol})$, and methanol/water $(6.81 \mathrm{~g} / 1.70 \mathrm{~g}, 80 / 20, \mathrm{w} / \mathrm{w})$ were weighed into a $25 \mathrm{~mL}$ round bottom flask to form a homogenous solution. The reaction mixture was purged with nitrogen for $20 \mathrm{~min}$, sealed, and immersed into a $70{ }^{\circ} \mathrm{C}$ preheated oil bath. The reaction was conducted for $36 \mathrm{~h}$ under 
magnetic stirring and quenched by immersing into an ice-water bath.

\section{Kinetic study of RAFT dispersion polymerization $\left(\left[\mathrm{mPEG}_{45}-\mathrm{DDMAT}\right] /[\mathrm{DDMAT}]=1 / 1,[\mathrm{St}]_{0} /[4 \mathrm{VP}]_{0}=4 / 1\right)$}

St (2.0 g, $19.2 \mathrm{mmol}), 4 \mathrm{VP}(0.50 \mathrm{~g}, 4.8 \mathrm{mmol}), \mathrm{mPEG}_{45}-\mathrm{DDMAT}$ (0.142 g, $0.06 \mathrm{mmol})$, DDMAT $(0.022 \mathrm{~g}, 0.06 \mathrm{mmol})$, AIBN $(0.0066 \mathrm{~g}, 0.04 \mathrm{mmol})$, and methanol/water $(11.35 \mathrm{~g} / 2.84 \mathrm{~g}, 80 /$ $20, \mathrm{w} / \mathrm{w}$ ) were weighed into a $25 \mathrm{~mL}$ round bottom flask to form a homogenous solution. The reaction mixture was purged with nitrogen for $20 \mathrm{~min}$, sealed, and immersed into a $70{ }^{\circ} \mathrm{C}$ preheated oil bath. Samples were extracted using syringes under nitrogen at different times. The obtained samples were characterized by ${ }^{1} \mathrm{H}$ NMR and THF GPC.

\section{Synthesis of $\mathrm{Ag}$ nanoparticles (NPs) supported by mPEG $_{45}-\mathrm{P}\left(\mathrm{St}_{108}-c o-4 \mathrm{VP}_{24}\right) / \mathbf{P}\left(\mathrm{St}_{108}-c o-4 \mathrm{VP}_{24}\right)$ assemblies}

A certain volume $(4 \mathrm{~mL})$ of $2.5 \mathrm{mM} \mathrm{AgNO}$ was introduced into $0.1 \mathrm{~g}(7.5 \% \mathrm{w} / \mathrm{w}) \mathrm{Ag} @ \mathrm{mPEG}_{45}-\mathrm{P}\left(\mathrm{St}_{108}-\mathrm{co}-4 \mathrm{VP}_{24}\right) / \mathrm{P}\left(\mathrm{St}_{108}-\mathrm{Co}-4 \mathrm{VP}_{24}\right)$ assemblies (prepared at $\left[\mathrm{mPEG}_{45}\right.$-DDMAT $] /[\mathrm{DDMAT}]=1 / 1$ ) dispersion and then stirred for $30 \mathrm{~min}$. Subsequently, a freshly prepared ice-cold $\mathrm{NaBH}_{4}$ solution $(1.0 \mathrm{~mL}, 0.6 \mathrm{M})$ was added dropwise slowly to the reaction mixture with gentle stirring and the reaction was conducted for $3 \mathrm{~h}$ at room temperature. The product was separated by centrifugation, rinsed with methanol/ water $(80 / 20, w / w)$, and centrifuged repeatedly. The final product was dispersed in methanol/water $(80 / 20, w / w)$ and stored at $4{ }^{\circ} \mathrm{C}$.

\section{Catalytic reduction experiments}

A dispersion of $\mathrm{Ag} @ \mathrm{mPEG}_{45}-\mathrm{P}\left(\mathrm{St}_{108}-\mathrm{co}-4 \mathrm{VP}_{24}\right) / \mathrm{P}\left(\mathrm{St}_{108}-\mathrm{co}-4 \mathrm{VP}_{24}\right)$ assemblies (containing $0.8 \mathrm{mg}$ composite assemblies) was mixed with an aqueous solution of $\mathrm{MB}(0.003 \mathrm{mM}, 10 \mathrm{~mL})$. Then, an aqueous solution of $\mathrm{NaBH}_{4}(0.6 \mathrm{M}, 1 \mathrm{~mL})$ was added to the mixture. The blue color of MB gradually vanished by catalytic reduction in the presence of reducing agents. The catalytic properties of $\mathrm{Ag} @ \mathrm{mPEG}_{45}-\mathrm{P}\left(\mathrm{St}_{108}-c o-4 \mathrm{VP}_{24}\right) / \mathrm{P}\left(\mathrm{St}_{108}-c o-4 \mathrm{VP}_{24}\right)$ assemblies were measured by monitoring the variation in the optical properties of the dye using a UV-vis spectrometer.

\section{Results and discussion}

As shown in Scheme 1, DDMAT and 4VP were utilized as the small molecular RAFT agent and solvophilic comonomer, respectively. The macro-RAFT agent was synthesized by esterification of monomethoxy poly(ethylene glycol) $\left(\mathrm{mPEG}_{45}\right)$ and DDMAT with a high esterification efficiency ( $>95 \%$, confirmed by ${ }^{1} \mathrm{H}$ NMR spectroscopy). St, one of the most commonly studied monomers in PISA research, was employed as the coreforming monomer. During the PISA of St and 4VP in a methanol/water $(80 / 20, \mathrm{w} / \mathrm{w})$ mixture at $70{ }^{\circ} \mathrm{C}$, blends of $\mathrm{mPEG}_{45^{-}}$ $\mathrm{P}\left(\mathrm{St}_{x}-c o-4 \mathrm{VP}_{y}\right)$ and $\mathrm{P}\left(\mathrm{St}_{x}-c o-4 \mathrm{VP}_{y}\right)$ form at the same time. DPs of block copolymer and homopolymer should be identical according to our previous work. ${ }^{34}$

Kinetic studies of RAFT dispersion polymerization of St and $4 \mathrm{VP}$ with different $[\mathrm{St}]_{0} /[4 \mathrm{VP}]_{0}$ molar ratios when targeting the DP of 200 for the core-forming block ([mPEG ${ }_{45}$-DDMAT]/ $[\mathrm{DDMAT}]=1 / 1)$ were shown in Fig. 1a. Increasing the amount of $4 \mathrm{VP}$ led to a lower rate of polymerization with only $72 \%$ monomer conversion being achieved within $36 \mathrm{~h}$ when the molar ratio of $[\mathrm{St}]_{0} /[4 \mathrm{VP}]_{0}$ was $2 / 1$. Fig. $1 \mathrm{~b}$ shows the evolution of St, $4 \mathrm{VP}$, and St/4VP monomer conversions with time ([St $]_{0} /$ $\left.[4 \mathrm{VP}]_{0}=4 / 1\right)$, it indicates that the rate of polymerization of St was slightly slower than that of $4 \mathrm{VP}$ during the early stage. After $12 \mathrm{~h}$ of reaction, the rate of polymerization of St was slight faster than that of 4VP. Overall, the rate of polymerization of St was close to that of $4 \mathrm{VP}$, suggesting the relatively uniform distribution of $4 \mathrm{VP}$ in the core-forming block. During the RAFT dispersion polymerization process with $[\mathrm{St}]_{0} /[4 \mathrm{VP}]_{0}=4 / 1$ (target DP of 200), it was found that the reaction became turbid at $2 \mathrm{~h}$, changed to bluish at $4 \mathrm{~h}$, and became milky white at around $10 \mathrm{~h}$ (see the inset image in Fig. 1c). This was consistent with the results of kinetic data, as shown in Fig. 1c. Since $4 \mathrm{VP}$ is a solvophilic monomer, increasing the amount of $4 \mathrm{VP}$ enhances the solvophilic property of the core-forming block, and thus results in a lower rate of polymerization. The semilogarithmic plot of RAFT dispersion polymerization of St and $4 \mathrm{VP}$ with $[\mathrm{St}]_{0} /[4 \mathrm{VP}]_{0}$ $=4 / 1$ and $\left[\mathrm{mPEG}_{45}\right.$-DDMAT] $/[$ DDMAT $]=1 / 1$ shows three regimes (see Fig. 1c). The first regime, which occurs between 0 to $2 \mathrm{~h}$, corresponding to the precipitation of $\mathrm{P}(\mathrm{St}-\mathrm{co}-4 \mathrm{VP})$ from the reaction mixture. In the second regime ( 2 to $12 \mathrm{~h}$ ), an
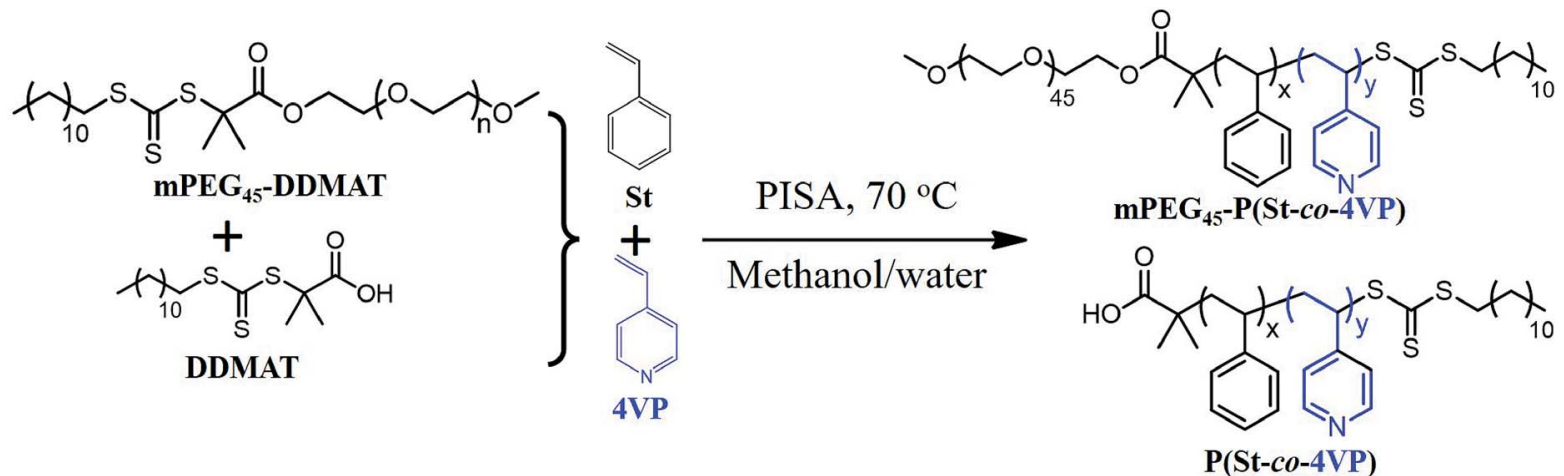

Scheme 1 RAFT dispersion polymerization of styrene and 4-vinylpyridine mediated by $\mathrm{mPEG}_{45}-\mathrm{DDMAT}$ and DDMAT in a methanol/water (80/ $20, w / w)$ mixture at $70^{\circ} \mathrm{C}$. 

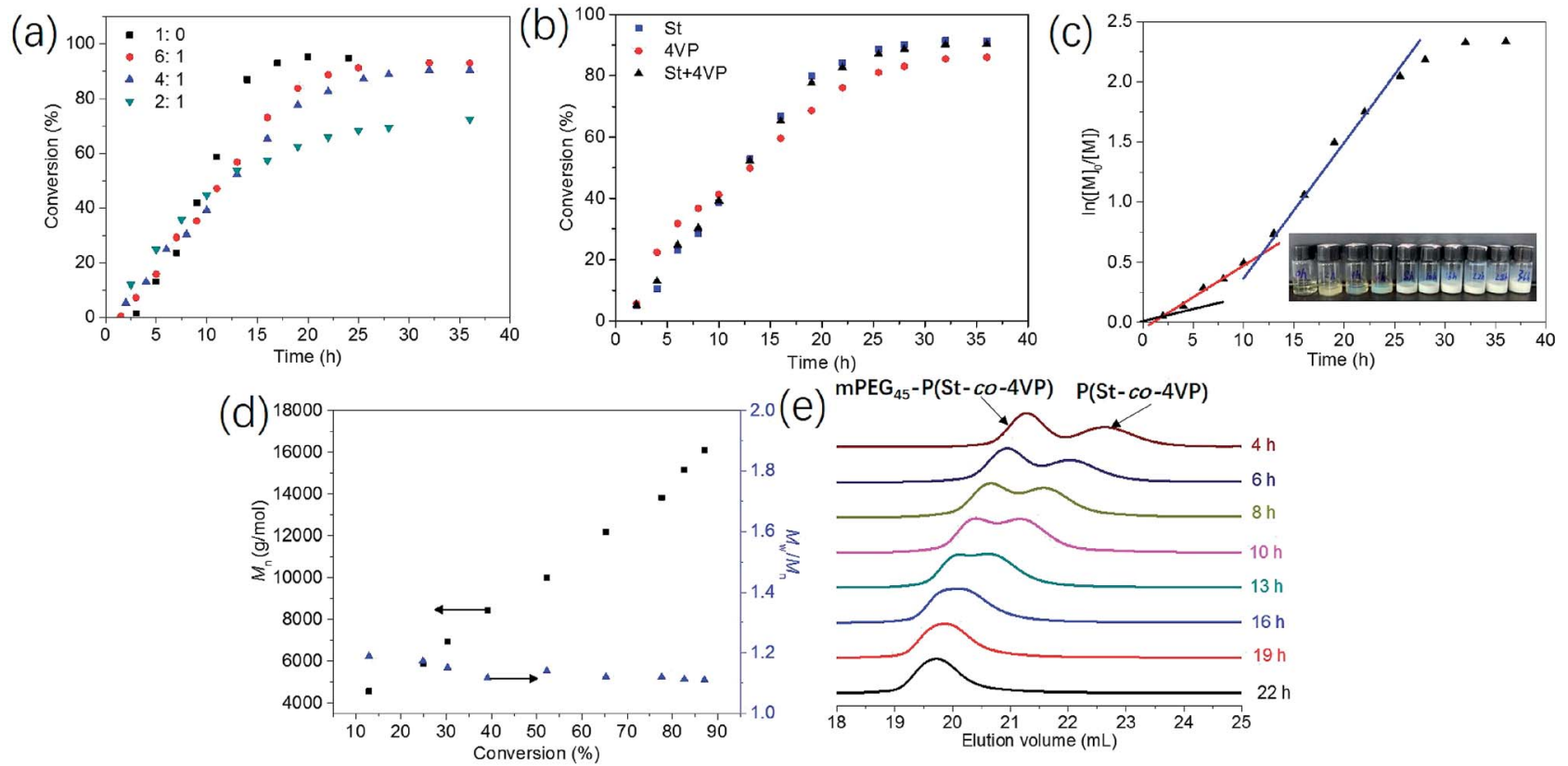

Fig. 1 (a) Kinetics of polymerization of St and $4 \mathrm{VP}$ at $70{ }^{\circ} \mathrm{C}$ at $15 \% \mathrm{w} / \mathrm{w}$ monomer concentration in a methanol/water mixture $(80 / 20, \mathrm{w} / \mathrm{w}) \mathrm{with}$ varying $[\mathrm{St}]_{0} /[4 \mathrm{VP}]_{0}$ molar ratios $\left(\left[\mathrm{mPEG}_{45}-\mathrm{DDMAT}\right] /[\mathrm{DDMAT}]=1 / 1\right.$, target DP of 200$)$. (b) Evolution of St, 4VP, and the overall monomer conversion with reaction time at $15 \% \mathrm{w} / \mathrm{w}$ monomer concentration in a methanol/water mixture $(80 / 20, \mathrm{w} / \mathrm{w})$ with the $[\mathrm{St}]_{0} /[4 \mathrm{VP}]_{0} \mathrm{molar}$ ratio of 4/1 ([mPEG $45-D D M A T] /[D D M A T]=1 / 1$, target DP of 200). (c) Plots of $\ln \left([\mathrm{M}]_{0} /[\mathrm{M}]\right)$ versus reaction time according to the data in (b). (d) Evolution of $M_{\mathrm{n}}$ and $M_{\mathrm{w}} / M_{\mathrm{n}}$ with monomer conversion for RAFT dispersion polymerization of St and 4VP in a methanol/water mixture (80/20, w/w) with $[\mathrm{St}]_{0} /[4 \mathrm{VP}]_{0}=4 / 1$ and $\left[\mathrm{mPEG}_{45}-\mathrm{DDMAT}\right] /[\mathrm{DDMAT}]=1 / 1$ (target DP of 200). (e) GPC traces of samples prepared via RAFT dispersion polymerization of St and $4 \mathrm{VP}$ in a methanol/water mixture $(80 / 20, \mathrm{w} / \mathrm{w})$ with $[\mathrm{St}]_{0} /[4 \mathrm{VP}]_{0}=4 / 1$ and $\left[\mathrm{mPEG}_{45}-\mathrm{DDMAT}\right] /[\mathrm{DDMAT}]=1 / 1$ (target DP of 200) at different reaction times.

increase in the rate of polymerization is observed, which corresponds to the solubilization of $\mathrm{P}(\mathrm{St}-c o-4 \mathrm{VP})$ with $\mathrm{mPEG}_{45^{-}}$ $\mathrm{P}(\mathrm{St}-c o-4 \mathrm{VP})$ and the formation of spherical nanoparticles. During this period, unreacted monomers enter the micellar cores to solvate the core-forming blocks, which leads to relatively high local monomer concentration in the micellar cores and thus the observed rate enhancement. ${ }^{30}$ In the third regime (12 to $36 \mathrm{~h}$ ), a further increase in the rate of polymerization was observed, which corresponds to further morphological evolution.

Samples extracted at different times were also analyzed by THF GPC, which confirmed the linear evolution of numberaverage molar mass $\left(M_{\mathrm{n}}\right)$ with monomer conversion, as shown in Fig. 1d. Fig. 1e shows GPC traces of the samples withdrawn at different times. Low molar mass distributions $\left(M_{\mathrm{w}} / M_{\mathrm{n}}<1.20\right)$ were observed throughout the polymerization. These characteristics are typical for a pseudo-living radical polymerization, indicating that good control is maintained under RAFT dispersion polymerization conditions in the presence of a small molecular RAFT agent and a solvophilic comonomer. Two separated GPC peaks were observed at low monomer conversions, corresponding to the presence of $\mathrm{mPEG}_{45}-\mathrm{P}\left(\mathrm{St}_{x}-c o-4 \mathrm{VP}_{y}\right)$ (the left one) and $\mathrm{P}\left(\mathrm{St}_{x}-c o-4 \mathrm{VP}_{y}\right)$ (the right one). This was further confirmed by the molar mass difference between two GPC peaks, which is equal to the $M_{\mathrm{n}}$ value of $\mathrm{mPEG}_{45}$-DDMAT as measured by THF GPC. As the monomer conversion increased, both GPC peaks shifted to low elution volume and changed to monomodal distributions. This is because the THF GPC equipment is unable to distinguish the molar mass difference between $\mathrm{mPEG}_{45}-\mathrm{P}\left(\mathrm{St}_{x}-c o-4 \mathrm{VP}_{y}\right)$ and $\mathrm{P}\left(\mathrm{St}_{x}-c o-4 \mathrm{VP}_{y}\right)$ when the molar mass is high enough.

Fig. 2 (TEM) and Fig. 3 (SEM) show the morphologies of polymer nano-objects prepared via RAFT dispersion polymerization of St and $4 \mathrm{VP}$ at different $[\mathrm{St}]_{0} /[4 \mathrm{VP}]_{0}$ molar ratios with $\left[\mathrm{mPEG}_{45}-\mathrm{DDMAT}\right] /[\mathrm{DDMAT}]=1 / 1$ (target DP of 200). Porous vesicles with smooth surface were obtained in the absence of 4VP as shown in Fig. 2a and 3a. In the presence of a small amount of $4 \mathrm{VP}\left([\mathrm{St}]_{0} /[4 \mathrm{VP}]_{0}=6 / 1\right)$, it was found that porous vesicles collapsed to form honeycomb-like large compound vesicles (LCVs) (Fig. 2b and 3b). When the molar ratio of [St $]_{0} /$ $[4 \mathrm{VP}]_{0}$ was $5 / 1$, honeycomb-like LCVs with loose internal structure were formed and the size of cells became smaller than that of $[\mathrm{St}]_{0} /[4 \mathrm{VP}]_{0}=6 / 1$ (Fig. $2 \mathrm{c}$ and $3 \mathrm{c}$ ). When the molar ratio of $[\mathrm{St}]_{0} /[4 \mathrm{VP}]_{0}$ was $4 / 1$, uniform honeycomb-like LCVs with more compact internal structure were observed. A large number of smaller cells were observed from the particle surface (Fig. $2 \mathrm{~d}$ and $3 \mathrm{~d})$. Decreasing the molar ratio of $[\mathrm{St}]_{0} /[4 \mathrm{VP}]_{0}$ to $3 / 1$ led to the formation of flower-like LCVs with large "petals" and the particle size increased to several micrometers (Fig. 2e and 3e). Further decreasing the molar ratio of $[\mathrm{St}]_{0} /[4 \mathrm{VP}]_{0}$ to $2 / 1$ decreased the complexity of the resultant assemblies with only lamellae being obtained. THF GPC analysis indicated that similar GPC data $\left(M_{\mathrm{n}}, M_{\mathrm{w}} / M_{\mathrm{n}}\right)$ were obtained with varying molar ratios of $[\mathrm{St}]_{0} /[4 \mathrm{VP}]_{0}$, as shown in Table S1. $\dagger^{1} \mathrm{H}$ NMR spectra of 

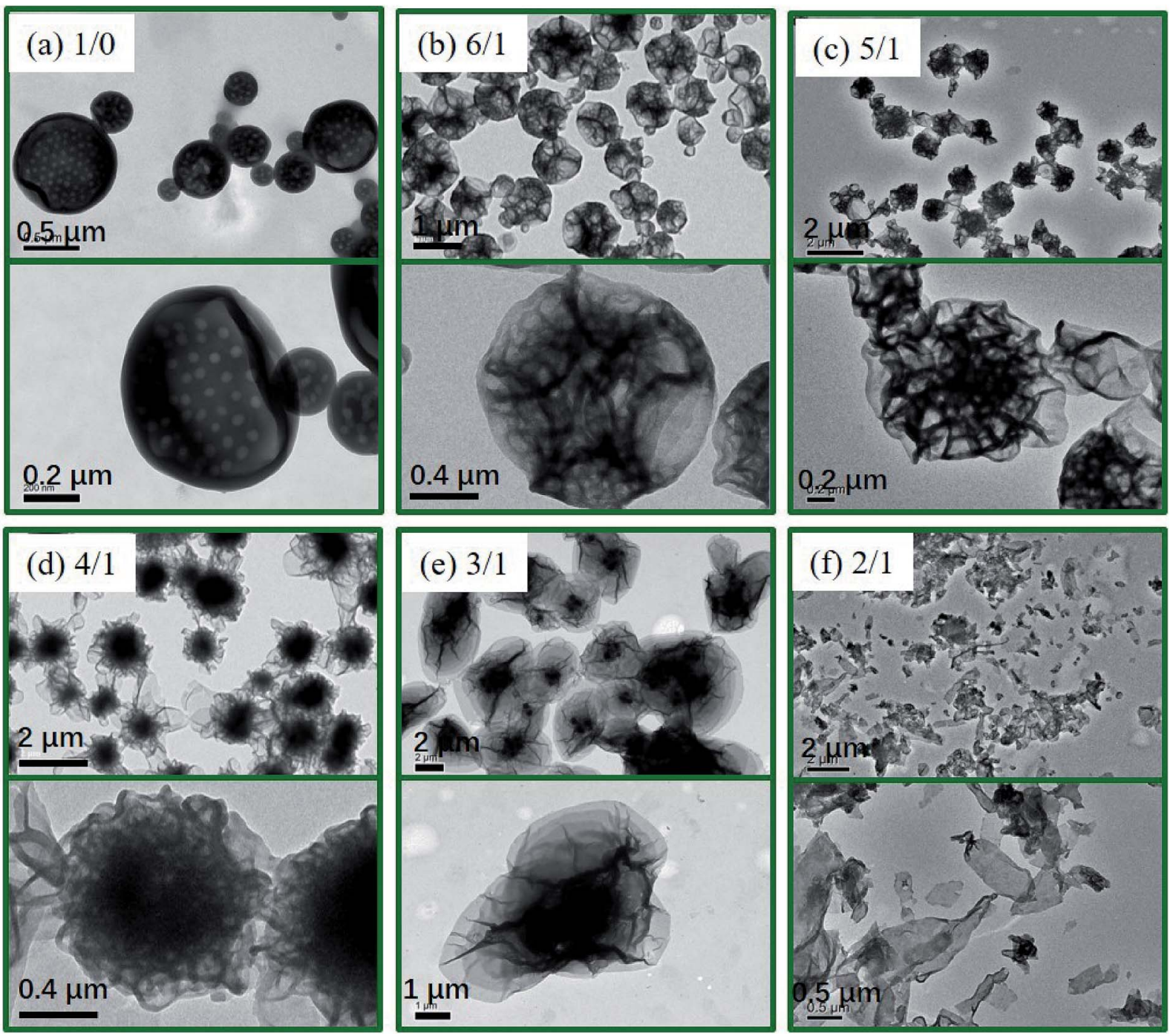

Fig. 2 TEM images of polymer nano-objects prepared via RAFT dispersion polymerization of St and $4 \mathrm{VP}$ at $70{ }^{\circ} \mathrm{C}$ in a methanol/water mixture (80/20, w/w) with varying [St] $/[4 \mathrm{VP}]_{0}$ molar ratios ([mPEG $\left.\left.45-\mathrm{DDMAT}\right] /[\mathrm{DDMAT}]=1 / 1\right)$ : (a) 1/0, $\mathrm{mPEG}_{45}-\mathrm{PSt}_{182} / \mathrm{PSt}_{182} ;(\mathrm{b}) 6 / 1, \mathrm{mPEG}_{45}-\mathrm{P}\left(\mathrm{St}_{133}-\right.$ $\left.\mathrm{co}-4 \mathrm{VP}_{18}\right) / \mathrm{P}\left(\mathrm{St}_{133}-\mathrm{co}-4 \mathrm{VP}_{18}\right)$; (c) $5 / 1, \mathrm{mPEG}_{45}-\mathrm{P}\left(\mathrm{St}_{124}-\mathrm{co}-4 \mathrm{VP}_{20}\right) / \mathrm{P}\left(\mathrm{St}_{124}-\mathrm{co}-4 \mathrm{VP}_{20}\right)$; (d) $4 / 1, \quad \mathrm{mPEG}_{45}-\mathrm{P}\left(\mathrm{St}_{108}-\mathrm{CO}-4 \mathrm{VP}_{24}\right) / \mathrm{P}\left(\mathrm{St}_{108}-\mathrm{CO}-4 \mathrm{VP} 24\right)$; (e) 3/1, mPEG $45-\mathrm{P}\left(\mathrm{St}_{93}-\mathrm{CO}-4 \mathrm{VP}_{31}\right) / \mathrm{P}\left(\mathrm{St}_{93}-\mathrm{CO}-4 \mathrm{VP}_{31}\right)$; (f) 2/1, $\mathrm{mPEG}_{45}-\mathrm{P}\left(\mathrm{St}_{96}-\mathrm{CO}-4 \mathrm{VP}_{49}\right) / \mathrm{P}\left(\mathrm{St}_{96}-\mathrm{CO}-4 \mathrm{VP}_{49}\right)$.

the samples further confirmed successful incorporation of $4 \mathrm{VP}$ in the assemblies (Fig. S2 $\dagger$ ). Control experiments of PISA were also carried out in the absence of DDMAT. As shown in Fig. S3, $\dagger$ changing the molar ratio of $[\mathrm{St}]_{0} /[4 \mathrm{VP}]_{0}$ from $6 / 1$ to $4 / 1$ had no significant effect on the morphology. Further decreasing the molar ratio of $[\mathrm{St}]_{0} /[4 \mathrm{VP}]_{0}$ led to gelation of the reaction mixture. These results indicate that both DDMAT and 4VP have significant effects on the formation of LCVs prepared via PISA of block copolymer and homopolymer.

The honeycomb-like LCVs prepared at $[\mathrm{St}]_{0} /[4 \mathrm{VP}]_{0}$ of $4 / 1$ (Fig. 2d and 3d) may be one of interesting block copolymer nano-objects. To better understand the formation process of the honeycomb-like LCVs, samples extracted during the kinetic study were diluted with methanol/water $(80 / 20, \mathrm{w} / \mathrm{w})$ and then characterized by TEM, as shown in Fig. 4 . It was found that nanospheres at $6 \mathrm{~h}$, nanospheres and vesicles at 8 and $10 \mathrm{~h}$, vesicles and a small amount of vesicular aggregates at $13 \mathrm{~h}$.
LCVs formed after $16 \mathrm{~h}$ and the internal structure became more and more compact. According to the TEM observations, two processes were involved in the formation of LCVs: (1) assembling $\mathrm{mPEG}_{45} \mathrm{P}(\mathrm{St}-c o-4 \mathrm{VP})$ and $\mathrm{P}(\mathrm{St}-c o-4 \mathrm{VP})$ into vesicles (Fig. 4a-d), a typical process of PISA; (2) aggregating and merging vesicles into LCVs (Fig. $4 \mathrm{~d}-\mathrm{h}$ ). In the absence of $4 \mathrm{VP}$, $\mathrm{mPEG}_{45}-\mathrm{PSt}$ and PSt form in situ during the PISA process. Since PSt is insoluble in the reaction mixture (methanol/water), PSt should be embedded inner the membrane of vesicles. In contrast, the addition of 4VP in PISA of block copolymer and homopolymer has a significant effect on the assemblies. A formation mechanism of the LCVs prepared via PISA of St and $4 \mathrm{VP}$ is proposed as shown in Scheme $2 . \mathrm{mPEG}_{45}-\mathrm{P}(\mathrm{St}-\mathrm{co}-4 \mathrm{VP})$ and $\mathrm{P}(\mathrm{St}-c o-4 \mathrm{VP})$ form in situ during the PISA process in the presence of $4 \mathrm{VP}$. The incorporation of $4 \mathrm{VP}$ increases the solvophilicity of $\mathrm{P}(\mathrm{St}-c o-4 \mathrm{VP})$, and thus drawing $\mathrm{P}(\mathrm{St}-c o-4 \mathrm{VP})$ from the inner of vesicle membrane to the surface to form domains. 

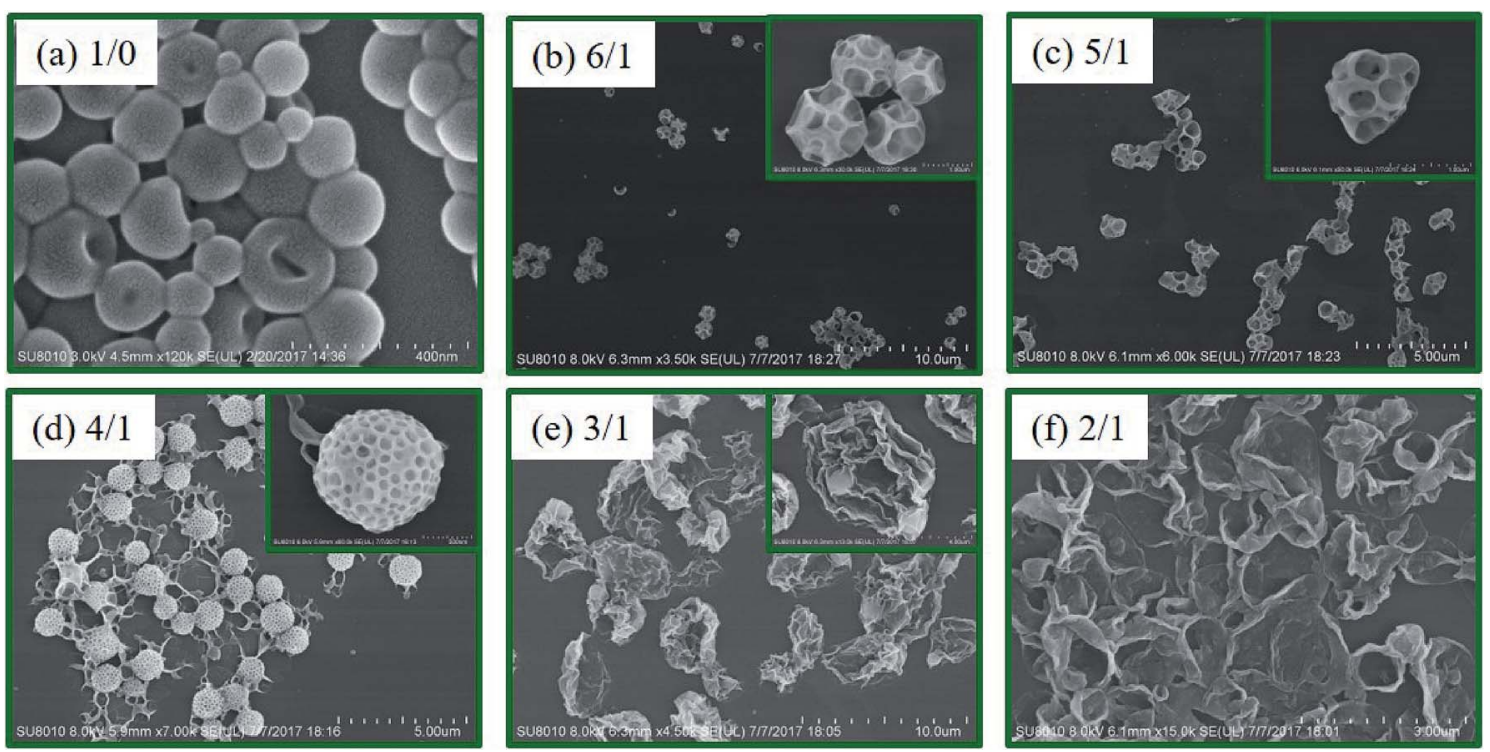

Fig. 3 SEM images of polymer nano-objects prepared via RAFT dispersion polymerization of St and $4 \mathrm{VP}$ at $70{ }^{\circ} \mathrm{C}$ in a methanol/water mixture (80/20, w/w) with varying [St] $]_{0} /[4 \mathrm{VP}]_{0}$ molar ratios ([mPEG $\left.\left.{ }_{45}-\mathrm{DDMAT}\right] /[\mathrm{DDMAT}]=1 / 1\right)$ : (a) 1/0, $\mathrm{mPEG}_{45}-\mathrm{PSt}_{168} / \mathrm{PSt}_{168} ;(\mathrm{b}) 6 / 1, \mathrm{mPEG}_{45}-\mathrm{P}\left(\mathrm{St}_{133^{-}}\right.$

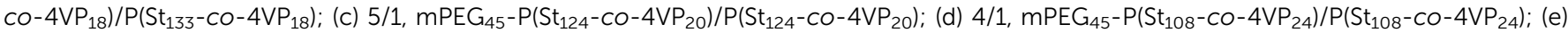
3/1, $\mathrm{mPEG}_{45}-\mathrm{P}\left(\mathrm{St}_{93}-\mathrm{CO}-4 \mathrm{VP}_{31}\right) / \mathrm{P}\left(\mathrm{St}_{93}-\mathrm{co}-4 \mathrm{VP}_{31}\right) ;(\mathrm{f}) 2 / 1, \mathrm{mPEG}_{45}-\mathrm{P}\left(\mathrm{St}_{96}-\mathrm{CO}-4 \mathrm{VP}_{49}\right) / \mathrm{P}\left(\mathrm{St}_{96}-\mathrm{CO}-4 \mathrm{VP}_{49}\right)$.

As the polymerization proceeds, the size of $\mathrm{P}(\mathrm{St}-\mathrm{co}-4 \mathrm{VP})$ domains without $\mathrm{mPEG}_{45}$ stabilization increases. To lower the interfacial energy inside and within vesicles, vesicles collapse and aggregate to form LCVs. As the polymerization further proceeds, reorganization of polymer chains occurs and the internal structure becomes more and more compact. This proposed mechanism indicates that both DDMAT and 4VP are crucial for preparing LCVs via PISA.

The molar ratio between $\mathrm{mPEG}_{45}-\mathrm{P}(\mathrm{St}-c o-4 \mathrm{VP})$ and $\mathrm{P}(\mathrm{St}-c o-$ $4 \mathrm{VP})$ is determined by the molar ratio of [ $\left.\mathrm{MPEG}_{45}-\mathrm{DDMAT}\right] /$ [DDMAT]. To justify the proposed mechanism, we then investigated the effect of $\left[\mathrm{MPEG}_{45}\right.$-DDMAT]/[DDMAT] molar ratio on the assemblies. Fig. 5 shows TEM images of polymer nano-objects prepared via PISA with $[\mathrm{St}]_{0} /[4 \mathrm{VP}]_{0}=4 / 1$ at different $\left[\mathrm{mPEG}_{45}\right.$-DDMAT]/[DDMAT] molar ratios (target DP of 200). Pure vesicles were formed with varying [mPEG 45 -DDMAT]/[DDMAT] molar ratios from $6 / 1$ to $3 / 1$, as shown in Fig. 5a-c. Decreasing the molar ratio of $\left[\mathrm{mPEG}_{45^{-}}\right.$ DDMAT]/[DDMAT] to $2 / 1$ led to the aggregation of vesicles (Fig. 5d). Further decreasing the molar ratio of $\left[\mathrm{mPEG}_{45^{-}}\right.$ DDMAT]/[DDMAT] to $1 / 1$ promoted the formation of LCVs with loose internal structure (Fig. 5e). When the molar ratio of [mPEG $_{45}$-DDMAT]/[DDMAT] was $1 / 2$, highly compact LCVs with holes inside were formed (Fig. 5f). The samples prepared at different [ $\left.\mathrm{mPEG}_{45}{ }^{-\mathrm{DDMAT}}\right] /[\mathrm{DDMAT}]$ molar ratios were also characterized by THF GPC, as shown in Fig. 6. Narrow molar mass distributions $\left(M_{\mathrm{w}} / M_{\mathrm{n}}<1.20\right)$ were observed in all cases. A new GPC peak was observed in the high elution volume (low molar mass) as the amount of DDMAT increased, which corresponds to the presence of $\mathrm{P}(\mathrm{St}-c o-4 \mathrm{VP})$. In general,
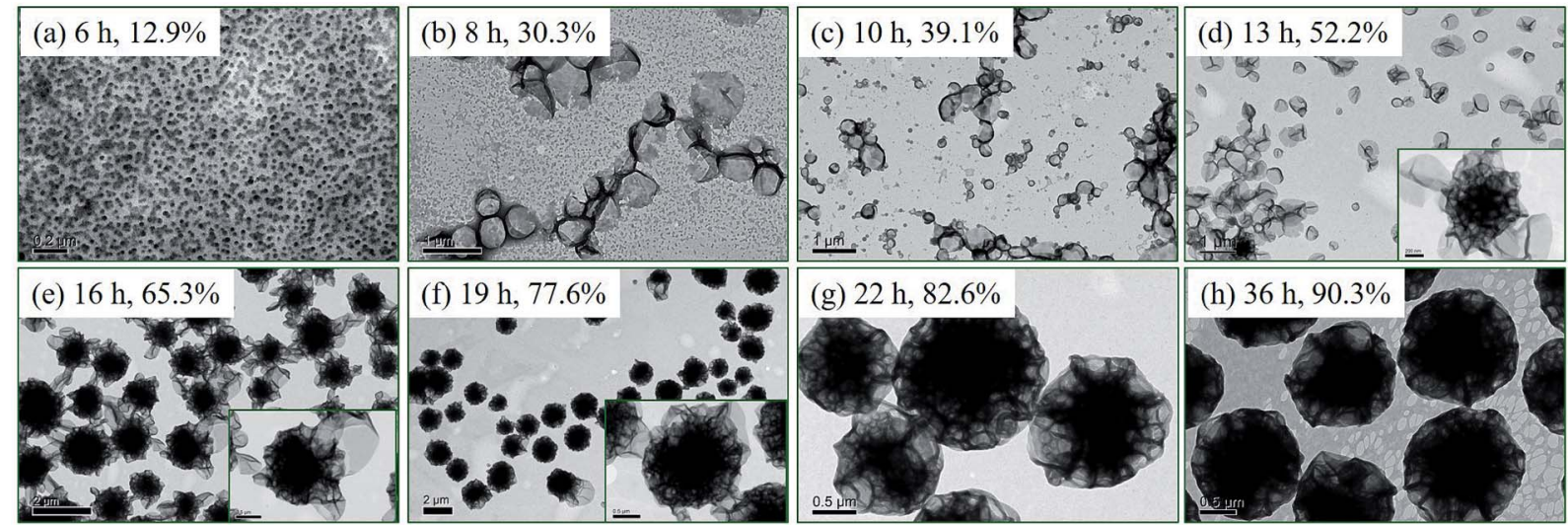

Fig. 4 TEM images of polymer nano-objects prepared via RAFT dispersion polymerization of St and 4VP in a methanol/water mixture (80/20, w/ w) with $[\mathrm{St}]_{0} /[4 \mathrm{VP}]_{0}=4 / 1$ and $\left[\mathrm{mPEG}_{45}-\mathrm{DDMAT}\right] /[\mathrm{DDMAT}]=1 / 1$ at different times. 


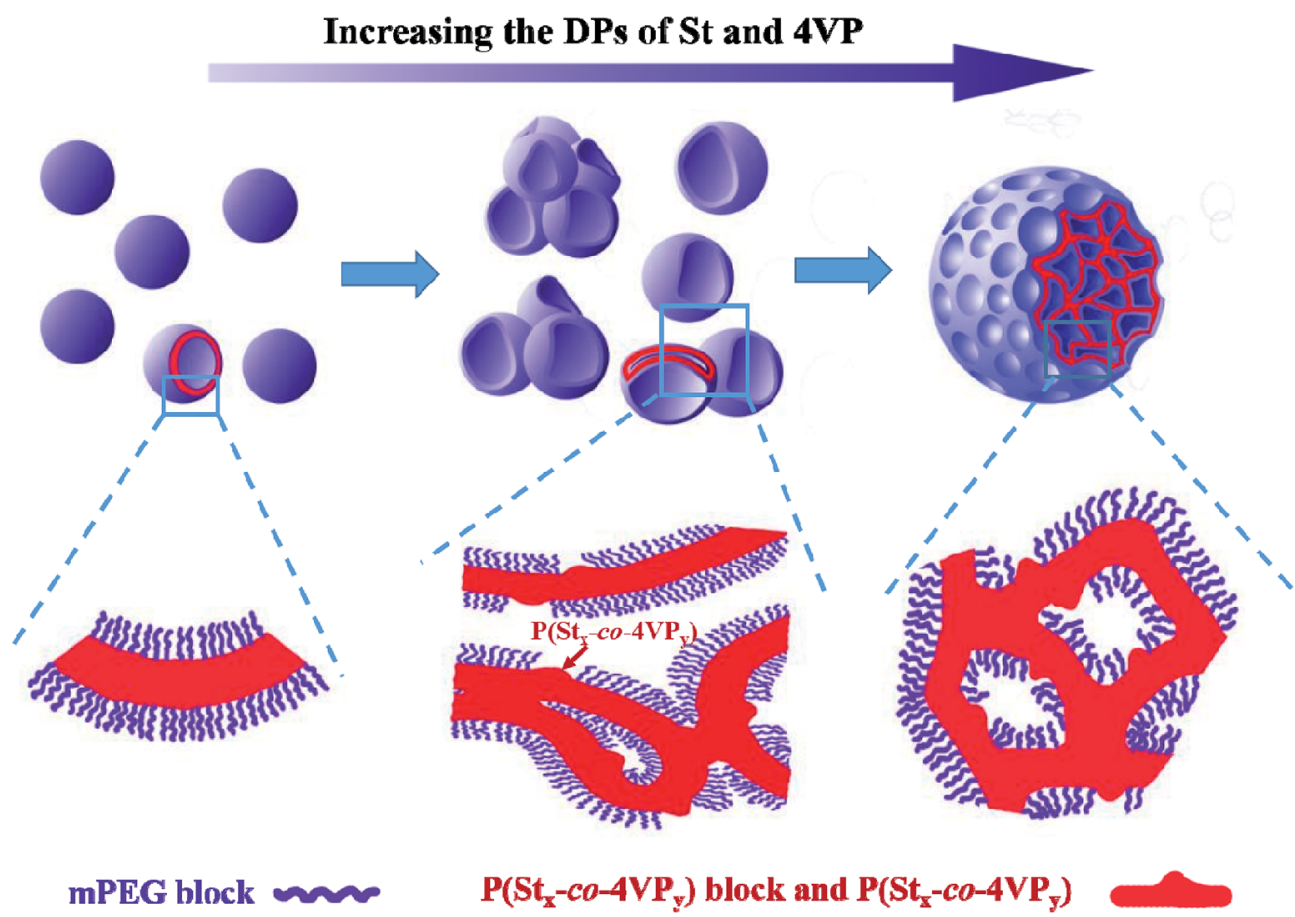

Scheme 2 Schematic illustration of the formation of large compound vesicles via RAFT dispersion polymerization of styrene and 4-vinylpyridine mediated by a binary mixture of $\mathrm{mPEG}_{45}-\mathrm{DDMAT}$ and DDMAT.

increasing the amount of $\mathrm{P}(\mathrm{St}-\mathrm{co}-4 \mathrm{VP})$ increases the number of domains on the vesicle surface, promoting the formation of LCVs. These results further support the formation mechanism of LCVs as we addressed above.

The solvent property has proven to be an important factor of RAFT dispersion polymerization, ${ }^{32,39}$ since the monomers are soluble in the reaction mixture and the resulted polymers are insoluble in the reaction mixture. RAFT dispersion polymerization of St and $4 \mathrm{VP}$ was performed at different methanol/water ratios $(\mathrm{w} / \mathrm{w})$ with $[\mathrm{St}]_{0} /[4 \mathrm{VP}]_{0}=4 / 1$ and $\left[\mathrm{mPEG}_{45}-\mathrm{DDMAT}\right] /$ $[$ DDMAT $]=1 / 1$ (target DP of 200). The TEM images are illustrated in Fig. 7, and the results are summarized in Table 1.
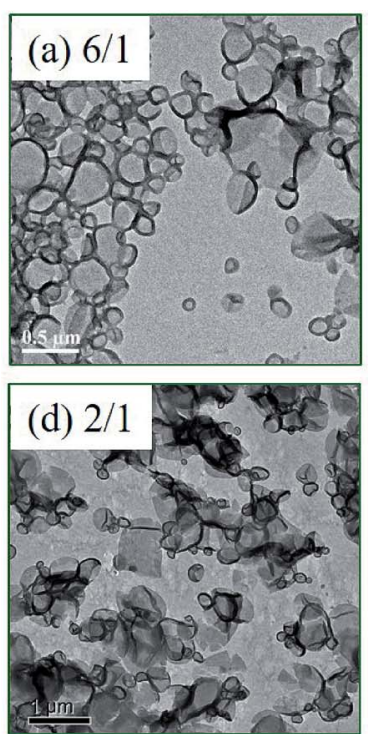
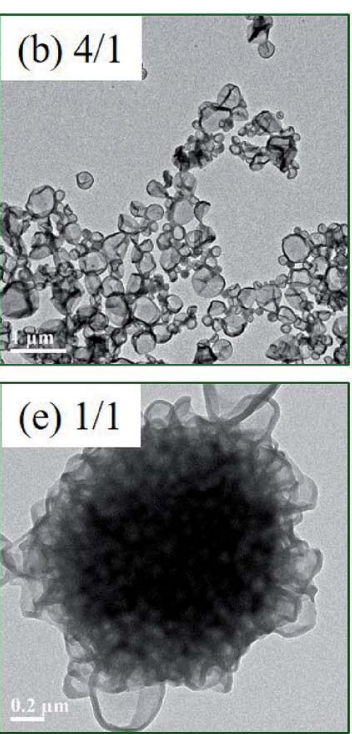
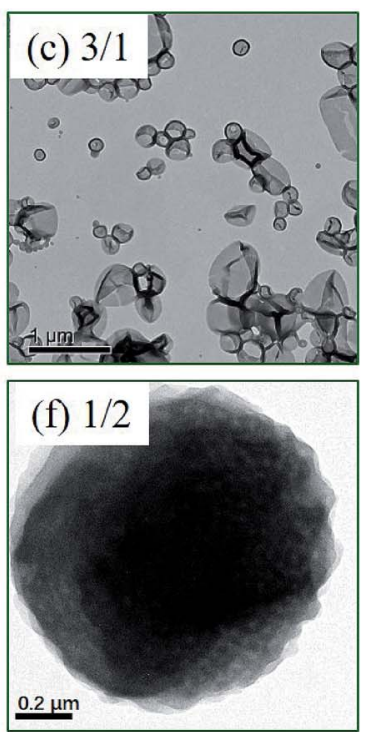

Fig. 5 TEM images of polymer nano-objects prepared via RAFT dispersion polymerization of St and $4 \mathrm{VP}$ at $70{ }^{\circ} \mathrm{C}$ in a methanol/water mixture $(80 / 20, w / w)$ with varying $\left[\mathrm{mPEG}_{45}-\mathrm{DDMAT}\right] /[\mathrm{DDMAT}]$ molar ratios ([St] $\left.]_{0} /[4 \mathrm{VP}]_{0}=4 / 1\right):(\mathrm{a}) 6 / 1, \mathrm{mPEG}_{45}-\mathrm{P}\left(\mathrm{St}_{118}-\mathrm{CO}-4 \mathrm{VP} \mathrm{P}_{26}\right) / \mathrm{P}\left(\mathrm{St}_{118}-\mathrm{CO}-4 \mathrm{VP} \mathrm{P}_{26}\right) ;(\mathrm{b})$

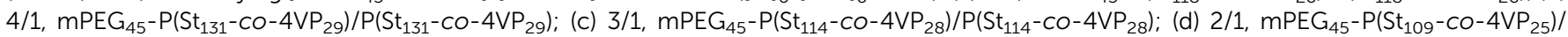
$\mathrm{P}\left(\mathrm{St}_{109}-\mathrm{co}-4 \mathrm{VP}_{25}\right)$; (e) 1/1, mPEG${ }_{45}-\mathrm{P}\left(\mathrm{St}_{108}-\mathrm{co}-4 \mathrm{VP}_{24}\right) / \mathrm{P}\left(\mathrm{St}_{108}-\mathrm{co}-4 \mathrm{VP}_{24}\right) ;$ (f) $1 / 2, \mathrm{mPEG}_{45}-\mathrm{P}\left(\mathrm{St}_{115}-\mathrm{co}-4 \mathrm{VP}_{25}\right) / \mathrm{P}\left(\mathrm{St}_{115}-\mathrm{Co}-4 \mathrm{VP} \mathrm{P}_{25}\right)$. 


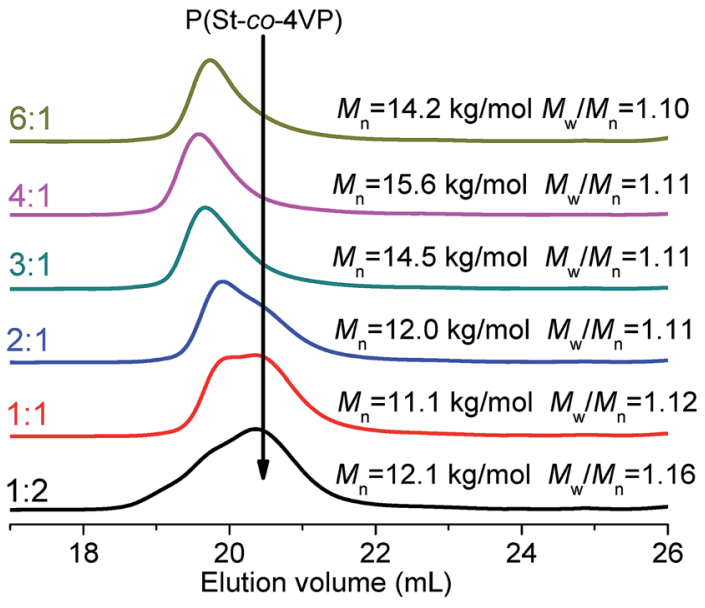

Fig. 6 GPC traces of polymer nano-objects prepared via RAFT dispersion polymerization of St and $4 \mathrm{VP}$ at $70{ }^{\circ} \mathrm{C}$ in a methanol/water mixture $(80 / 20, \mathrm{w} / \mathrm{w})$ with varying $\left[\mathrm{mPEG}_{45}-\mathrm{DDMAT}\right] /[\mathrm{DDMAT}]$ molar ratios $\left([\mathrm{St}]_{0} /[4 \mathrm{VP}]_{0}=4 / 1\right)$.

When the ratio of methanol/water (w/w) was 70/30, pure vesicles were observed as shown in Fig. 7a. As the methanol/water ratio $(\mathrm{w} / \mathrm{w})$ increased to $75 / 25$, vesicles and collapsed porous vesicles coexisted (Fig. 7b). Further increasing the methanol/water ratio $(\mathrm{w} / \mathrm{w})$ to $80 / 20$ or $85 / 15$, LCVs were observed in both cases. These results demonstrate that increasing the methanol content facilitates the formation of LCVs via PISA of St and 4VP using a binary mixture of mPEG $_{45}$-DDMAT and DDMAT. According to the data in Table 1, it was found that more 4VP was incorporated into the core-forming block as the methanol content increased, which should be the reason of morphological transformation. For RAFT dispersion polymerization, the reaction process can be divided into homogenous polymerization and heterogenous polymerization. During the homogenous polymerization stage, the resulted polymer chains are soluble in the reaction mixture. Thus the kinetics of St and $4 \mathrm{VP}$ should be similar, since the reactivity ratios between St and $4 \mathrm{VP}$ are similar. ${ }^{68}$ During the heterogenous polymerization stage, the polymerization mainly occurs in the monomer-swollen micellar cores. As $4 \mathrm{VP}$ is a solvophilic comonomer, $4 \mathrm{VP}$ is prone to stay in the reaction mixture rather than in the monomer-swollen micellar cores. As a result, more $4 \mathrm{VP}$ should be incorporated in the core-forming block when the heterogenous polymerization stage becomes shorter. A higher methanol content in the reaction mixture leads to longer nucleation, leading to a shorter heterogenous polymerization stage. ${ }^{39}$ Therefore, increasing the methanol content promotes the formation of LCVs via PISA of St and $4 \mathrm{VP}$ in the presence of $\mathrm{mPEG}_{45}$-DDMAT and DDMAT.

Typically, the morphology of block copolymer prepared via PISA is primarily dictated by the relative volume fractions of solvophilic and solvophobic blocks. ${ }^{18}$ Therefore, DP of the coreforming block should be an important parameter that has a significant effect on the final assemblies. Fig. 8 shows TEM images of polymer nano-objects prepared via RAFT dispersion polymerization of St and $4 \mathrm{VP}$ with $[\mathrm{St}]_{0} /[4 \mathrm{VP}]_{0}=4 / 1$ and $\left[\mathrm{mPEG}_{45^{-}}\right.$ DDMAT $] /[$ DDMAT $]=1 / 1$, targeting DP of 100, 150, 250. When the target DP was 100, spherical nanoparticles were observed, as shown in Fig. 8a. When the target DP was 150, mixed morphology with vesicles and nanospheres being obtained (Fig. 8b). When the target DP was increased to 200, LCVs with loose internal structure were observed (Fig. 7c). Further increasing the target DP to 250 led to the formation of LCVs with compact internal structure. Increasing DPs of $\mathrm{mPEG}_{45} \mathrm{P}(\mathrm{St}-\mathrm{co}-4 \mathrm{VP})$ and $\mathrm{P}(\mathrm{St}-\mathrm{co}-$ $4 \mathrm{VP}$ ) increases the volume fraction of solvophobic block, promoting the formation of higher-order morphologies. On the other hand, increasing DPs of $\mathrm{mPEG}_{45}-\mathrm{P}(\mathrm{St}-\mathrm{co}-4 \mathrm{VP})$ and $\mathrm{P}(\mathrm{St}-\mathrm{co}-$
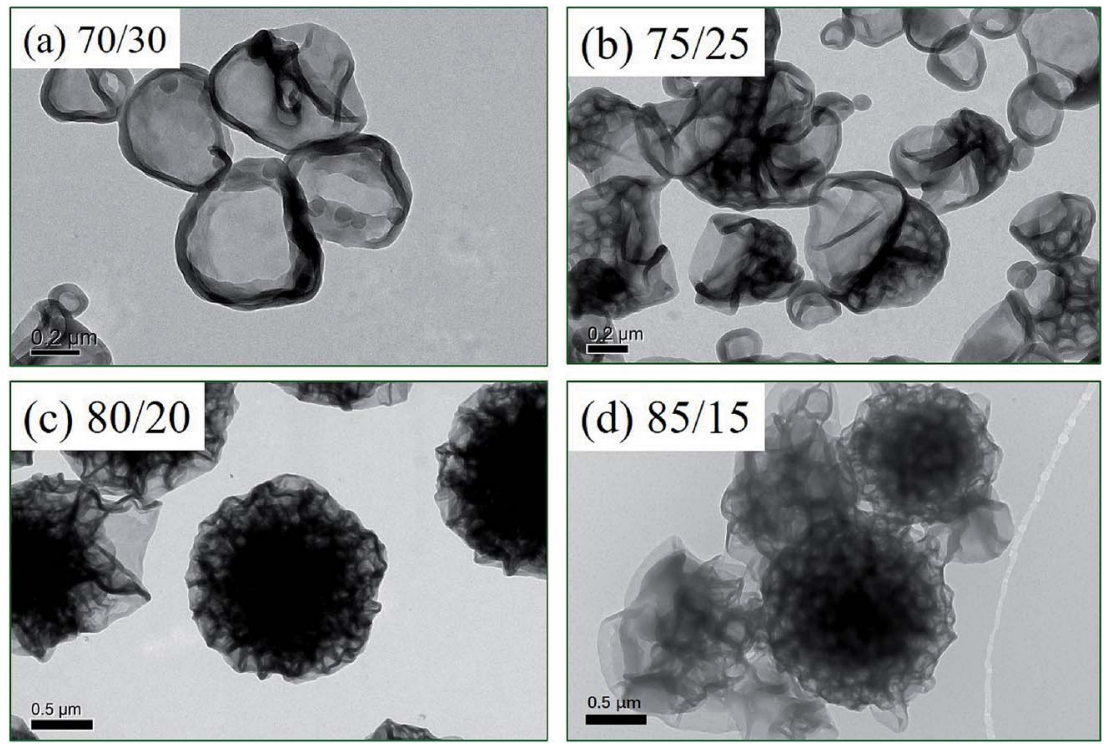

Fig. 7 TEM images of polymer nano-objects prepared via RAFT dispersion polymerization of St and $4 \mathrm{VP}$ at $70{ }^{\circ} \mathrm{C}$ with $[\mathrm{St}]_{0} /[4 \mathrm{VP}]_{0}=4 / 1$ and $\left[\mathrm{mPEG}_{45}-\mathrm{DDMAT}\right] /[\mathrm{DDMAT}]=1 / 1$ in methanol/water mixtures with different methanol/water ratios $(\mathrm{w} / \mathrm{w}):(\mathrm{a}) 70 / 30, \mathrm{mPEG}_{45}-\mathrm{P}\left(\mathrm{St} \mathrm{t}_{121}-\mathrm{CO}-4 \mathrm{VP} \mathrm{P}_{22}\right) /$ $\mathrm{P}\left(\mathrm{St}_{121}-\mathrm{co}-4 \mathrm{VP}_{22}\right)$; (b) 75/25, $\mathrm{mPEG}_{45}-\mathrm{P}\left(\mathrm{St}_{131}-\mathrm{co}-4 \mathrm{VP}_{28}\right) / \mathrm{P}\left(\mathrm{St}_{131}-\mathrm{co}-4 \mathrm{VP}_{28}\right)$; (c) 80/20, mPEG $\mathrm{H}_{45}-\mathrm{P}\left(\mathrm{St}_{108}-\mathrm{co}-4 \mathrm{VP}_{24}\right) / \mathrm{P}\left(\mathrm{St}_{108}-\mathrm{co}-4 \mathrm{VP} 24\right) ;(\mathrm{d}) 85 / 15$, $\mathrm{mPEG}_{45}-\mathrm{P}\left(\mathrm{St}_{115}-\mathrm{CO}-4 \mathrm{VP}_{27}\right) / \mathrm{P}\left(\mathrm{St}_{115}-\mathrm{CO}-4 \mathrm{VP}_{27}\right)$. 


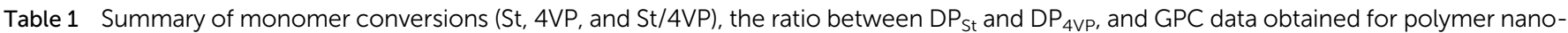
objects synthesized at $15 \% \mathrm{w} / \mathrm{w}$ monomer concentration via RAFT dispersion polymerization of St and $4 \mathrm{VP}$ at $70{ }^{\circ} \mathrm{C}$ with $[\mathrm{St}]_{0} /[4 \mathrm{VP}]_{0}=4 / 1$ and $\left[\mathrm{mPEG}_{45}-\mathrm{DDMAT}\right] /[\mathrm{DDMAT}]=1 / 1$ in methanol/water mixtures with different methanol/water ratios

\begin{tabular}{|c|c|c|c|c|c|c|c|}
\hline Exp. & $\begin{array}{l}\text { Methanol/water } \\
(\mathrm{w} / \mathrm{w})\end{array}$ & $\begin{array}{l}\text { Conversion } \\
(\mathrm{St})(\%)\end{array}$ & $\begin{array}{l}\text { Conversion } \\
(4 \mathrm{VP})(\%)\end{array}$ & $\begin{array}{l}\text { Monomer conversion } \\
(\%)\end{array}$ & $\mathrm{DP}_{\mathrm{St}} / \mathrm{DP}_{4 \mathrm{VP}}$ & $M_{\mathrm{n}}\left(\mathrm{kg} \mathrm{mol} \mathrm{mol}^{-1}\right)$ & $M_{\mathrm{w}} / M_{\mathrm{n}}$ \\
\hline 1 & $70 / 30$ & 75.7 & 53.9 & 71.3 & 5.62 & 12.0 & 1.09 \\
\hline 2 & $75 / 25$ & 81.6 & 69.3 & 79.1 & 4.71 & 13.2 & 1.11 \\
\hline 3 & $80 / 20$ & 79.8 & 68.8 & 77.6 & 4.64 & 13.8 & 1.12 \\
\hline 4 & $85 / 15$ & 71.9 & 67.5 & 71.0 & 4.26 & 10.8 & 1.15 \\
\hline
\end{tabular}
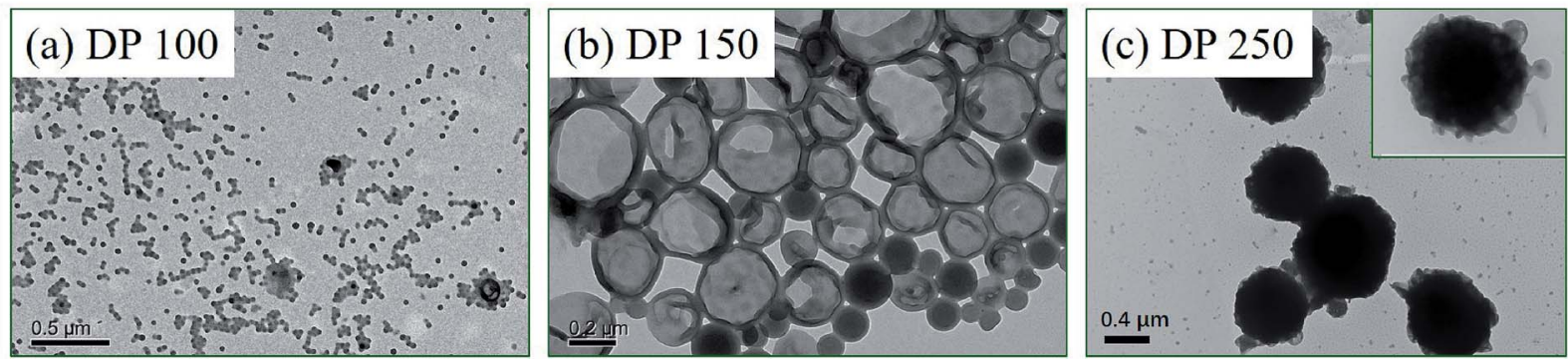

Fig. 8 TEM images of polymer nano-objects prepared via RAFT dispersion polymerization of St and $4 \mathrm{VP}$ with $\left[\mathrm{St}_{0} /[4 \mathrm{VP}]_{0}=4 / 1\right.$ and $\left[\mathrm{mPEG}_{45^{-}}\right.$ $\mathrm{DDMAT} /[\mathrm{DDMAT}]=1 / 1$, targeting DP: (a) $100, \mathrm{mPEG}_{45}-\mathrm{P}\left(\mathrm{St}_{63}-\mathrm{co}-4 \mathrm{VP}_{16}\right) / \mathrm{P}\left(\mathrm{St}_{63}-\mathrm{co}-4 \mathrm{VP}_{16}\right) ;$ (b) $150, \mathrm{mPEG}_{45}-\mathrm{P}\left(\mathrm{St}_{78}-\mathrm{Co}-4 \mathrm{VP} 19\right) / \mathrm{P}\left(\mathrm{St}_{78}-\mathrm{co}-\right.$ $\left.4 \mathrm{VP}_{19}\right) ;$ (c) $250, \mathrm{mPEG}_{45}-\mathrm{P}\left(\mathrm{St}_{136}-\mathrm{co}-4 \mathrm{VP}_{26}\right) / \mathrm{P}\left(\mathrm{St}_{136}-\mathrm{co}-4 \mathrm{VP}_{26}\right)$.

4VP) also leads to larger $\mathrm{P}(\mathrm{St}-\mathrm{co}-4 \mathrm{VP})$ domains, which facilitates the formation of LCVs as we addressed above.

LCVs prepared via the current PISA formulation containing a certain amount of $4 \mathrm{VP}$ in the core-forming block. Pyridine group has proven to be an important function group for the preparation of inorganic/organic composite materials. ${ }^{70-73}$ Herein, we attached $\mathrm{Ag}$ nanoparticles to $\mathrm{mPEG}_{45}-\mathrm{P}\left(\mathrm{St}_{108}-\mathrm{co}\right.$ $\left.4 \mathrm{VP}_{24}\right) / \mathrm{P}\left(\mathrm{St}_{108}-c o-4 \mathrm{VP}_{24}\right)$ LCVs (prepared at [ $\left.\mathrm{mPEG}_{45}-\mathrm{DDMAT}\right] /$ [DDMAT] = 1/1) via in situ reduction of $\mathrm{AgNO}_{3}$ using $\mathrm{NaBH}_{4}$. Fig. 9a and b show TEM images of the obtained Ag@mPEG ${ }_{45^{-}}$
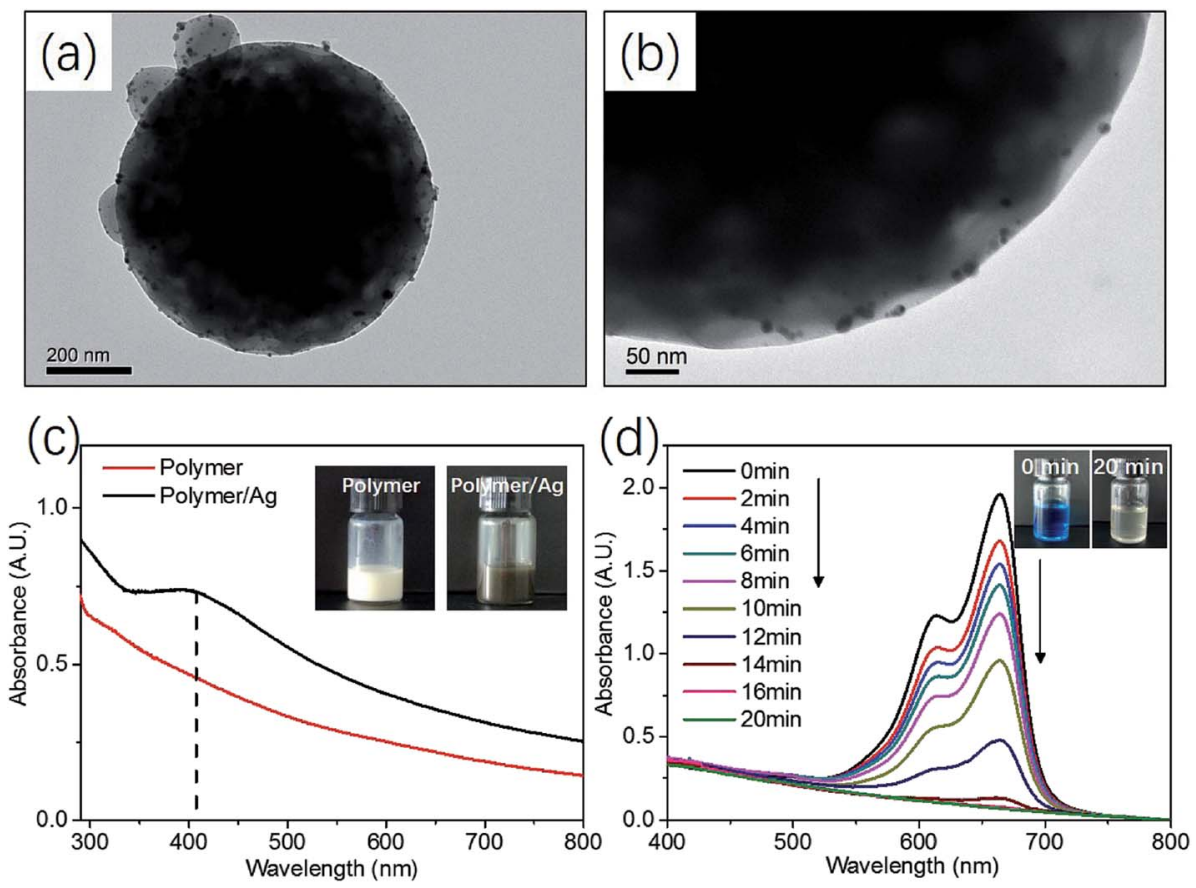

Fig. 9 (a), (b) $\mathrm{Ag}\left(\mathrm{amPEG}_{45}-\mathrm{P}\left(\mathrm{St}_{108}-\mathrm{CO}-4 \mathrm{VP}_{24}\right) / \mathrm{P}\left(\mathrm{St}_{108}-\mathrm{CO}-4 \mathrm{VP}_{24}\right) \mathrm{LCV}\right.$ s prepared via in situ reduction of $\mathrm{AgNO}_{3}$. (c) UV-vis spectra of dispersions of $\mathrm{mPEG}_{45}-\mathrm{P}\left(\mathrm{St}_{108}-\mathrm{CO}-4 \mathrm{VP}_{24}\right) / \mathrm{P}\left(\mathrm{St}_{108}-\mathrm{CO}-4 \mathrm{VP}_{24}\right) \mathrm{LCVs}$ (the red line) and $\mathrm{Ag}\left(\mathrm{amPEG} \mathrm{G}_{45}-\mathrm{P}\left(\mathrm{St}_{108}-\mathrm{CO}-4 \mathrm{VP}_{24}\right) / \mathrm{P}\left(\mathrm{St}_{108}-\mathrm{CO}-4 \mathrm{VP} 24\right) \mathrm{LCVs}\left(\mathrm{the}_{2}\right.\right.$ black line). (d) UV-vis spectra of $\mathrm{MB}$ reduced with $\mathrm{NaBH}_{4}$ using $A g\left(\mathrm{mPEG}_{45}-\mathrm{P}\left(\mathrm{St}_{108}-\mathrm{CO}-4 \mathrm{VP}_{24}\right) / \mathrm{P}\left(\mathrm{St}_{108}-\mathrm{CO}-4 \mathrm{VP}_{24}\right) \mathrm{LCVs}\right.$ as a catalysis. 
$\mathrm{P}\left(\mathrm{St}_{108}-\mathrm{Co}-4 \mathrm{VP}_{24}\right) / \mathrm{P}\left(\mathrm{St}_{108}-\mathrm{co}-4 \mathrm{VP}_{24}\right)$ LCVs and a number of black dots were observed on the LCVs, indicating the formation of $\mathrm{Ag}$ nanoparticles. UV-vis spectroscopy measurement further confirmed the formation of $\mathrm{Ag}$ nanoparticles with an absorption band at around $410 \mathrm{~nm}$, as shown in Fig. 9c. The color of reaction mixture changed from white to brownish after the reduction of $\mathrm{AgNO}_{3}$ (see the inset image of Fig. 9c). The catalytic property of the $\mathrm{Ag} @ \mathrm{mPEG}_{45}-\mathrm{P}\left(\mathrm{St}_{108}-\mathrm{co}-4 \mathrm{VP}_{24}\right) / \mathrm{P}\left(\mathrm{St}_{108}-c o-4 \mathrm{VP}_{24}\right)$ LCVs was then studied by the catalysis of methyl blue (MB) using $\mathrm{NaBH}_{4}$. UV-vis spectra of the solution at different time points indicated the reduction of $\mathrm{MB}$, with the absorption bands at 615 and $665 \mathrm{~nm}$ being decreased with time, as shown in Fig. 9d. After the addition of $\mathrm{Ag} @ \mathrm{mPEG}_{45}-\mathrm{P}\left(\mathrm{St}_{108}-\mathrm{Co}-4 \mathrm{VP}_{24}\right) /$ $\mathrm{P}\left(\mathrm{St}_{108}-\mathrm{Co}-4 \mathrm{VP}_{24}\right)$ LCVs, the color of the solution became pale gradually and transparent eventually, as shown in the inset image of Fig. 9d.

\section{Conclusion}

In summary, a new PISA formulation via RAFT dispersion polymerization of St and 4VP mediated by using a binary mixture of mPEG $_{45}$-DDMAT and DDMAT in methanol/water at $70{ }^{\circ} \mathrm{C}$ has been developed. Kinetic studies suggested that increasing the amount of $4 \mathrm{VP}$ led to a lower rate of polymerization. GPC analysis demonstrated the linear evolution of $M_{\mathrm{n}}$ with monomer conversion with low molar mass distributions, confirming its pseudo-living character. By varying the molar ratios of $[\mathrm{St}]_{0} /[4 \mathrm{VP}]_{0}\left(\left[\mathrm{mPEG}_{45}-\mathrm{DDMAT}\right] /[\mathrm{DDMAT}]=1 / 1\right)$, the morphologies changed from porous vesicles $(1 / 0)$ to LCVs (from $6 / 1$ to $3 / 1$ ) to lamellae (2/1). TEM observations demonstrated that two processes were involved in the formation of LCVs: (1) assembling $\mathrm{mPEG}_{45}-\mathrm{P}(\mathrm{St}-\mathrm{co}-4 \mathrm{VP})$ and $\mathrm{P}(\mathrm{St}-\mathrm{co}-4 \mathrm{VP})$ into vesicles, a typical process of PISA; (2) aggregating and merging vesicles into LCVs. Effects of [ $\mathrm{mPEG}_{45}$-DDMAT]/[DDMAT] molar ratio, methanol/water ratio, and DP of the core-forming block were studied in detail. The results demonstrated that low $\left[\mathrm{mPEG}_{45^{-}}\right.$ DDMAT]/[DDMAT] molar ratio, high methanol/water ratio, and high DP of the core-forming block facilitated the formation of LCVs via PISA of St and 4VP. Ag@mPEG $45_{5}-\mathrm{P}\left(\mathrm{St}_{108}-\mathrm{co}-4 \mathrm{VP}_{24}\right)$ / $\mathrm{P}\left(\mathrm{St}_{108}-\mathrm{Co}-4 \mathrm{VP}_{24}\right)$ LCVs were prepared by in situ reduction of $\mathrm{AgNO}_{3}$ using $\mathrm{NaBH}_{4}$. The obtained Ag@mPEG $\mathrm{Am}_{45} \mathrm{P}\left(\mathrm{St}_{108}-\mathrm{Co}-\right.$ $\left.4 \mathrm{VP}_{24}\right) / \mathrm{P}\left(\mathrm{St}_{108}-\mathrm{co}-4 \mathrm{VP}_{24}\right)$ LCVs exhibited catalytic property by reducing $\mathrm{MB}$ with $\mathrm{NaBH}_{4}$.

\section{Conflicts of interest}

There are no conflicts to declare.

\section{Acknowledgements}

The authors acknowledge support from the National Natural Science Foundation of China (Grant 21504017), Guangdong Natural Science Foundation (Grant 2016A030310339), Science and Technology Planning Project of Guangdong Province (Grant 2017A010103045), and Science and Technology Program of Guangzhou (Grant 201707010420).

\section{References}

1 Z. Wang, M. C. M. van Oers, F. P. J. T. Rutjes and J. C. M. van Hest, Polymersome Colloidosomes for Enzyme Catalysis in a Biphasic System, Angew. Chem., Int. Ed., 2012, 51(43), 10746-10750, DOI: 10.1002/anie.201206555.

2 I. Louzao and J. C. M. van Hest, Permeability Effects on the Efficiency of Antioxidant Nanoreactors, Biomacromolecules, 2013, 14(7), 2364-2372, DOI: 10.1021/bm400493b.

3 T. Liu, J. Hu, Z. Jin, F. Jin and S. Liu, Two-Photon Ratiometric Fluorescent Mapping of Intracellular Transport Pathways of pH-Responsive Block Copolymer Micellar Nanocarriers, $A d v$. Healthcare Mater., 2013, 2(12), 1576-1581, DOI: 10.1002/ adhm.201200436.

4 J. S. Lee and J. Feijen, Polymersomes for Drug Delivery: Design, Formation and Characterization, J. Controlled Release, 2012, 161(2), 473-483, DOI: 10.1016/j.jconrel.2011.10.005.

5 Y. Ning, L. A. Fielding, T. S. Andrews, D. J. Growney and S. P. Armes, Sulfate-Based Anionic Diblock Copolymer Nanoparticles for Efficient Occlusion within Zinc Oxide, Nanoscale, 2015, 7(15), 6691-6702, DOI: 10.1039/ C5NR00535C.

6 X. Hu, J. Hu, J. Tian, Z. Ge, G. Zhang, K. Luo and S. Liu, Polyprodrug Amphiphiles: Hierarchical Assemblies for Shape-Regulated Cellular Internalization, Trafficking, and Drug Delivery, J. Am. Chem. Soc., 2013, 135(46), 1761717629, DOI: 10.1021/ja409686x.

7 X. Hu, G. Liu, Y. Li, X. Wang and S. Liu, Cell-Penetrating Hyperbranched Polyprodrug Amphiphiles for Synergistic Reductive Milieu-Triggered Drug Release and Enhanced Magnetic Resonance Signals, J. Am. Chem. Soc., 2014, 137(1), 362-368, DOI: 10.1021/ja5105848.

8 Y. Mai and A. Eisenberg, Self-Assembly of Block Copolymers, Chem. Soc. Rev., 2012, 41(18), 5969-5985, DOI: 10.1039/ C2CS35115C.

9 J. Du, Y. Tang, A. L. Lewis and S. P. Armes, pH-Sensitive Vesicles Based on a Biocompatible Zwitterionic Diblock Copolymer, J. Am. Chem. Soc., 2005, 127(51), 17982-17983, DOI: $10.1021 /$ ja056514l.

10 K. Kita-Tokarczyk, J. Grumelard, T. Haefele and W. Meier, Block Copolymer Vesicles-using Concepts from Polymer Chemistry to Mimic Biomembranes, Polymer, 2005, 46(11), 3540-3563, DOI: 10.1016/j.polymer.2005. 02.083 .

11 A. Blanazs, M. Massignani, G. Battaglia, S. P. Armes and A. J. Ryan, Tailoring Macromolecular Expression at Polymersome Surfaces, Adv. Funct. Mater., 2009, 19(18), 2906-2914, DOI: 10.1002/adfm.200900201.

12 M. Moffitt, K. Khougaz and A. Eisenberg, Micellization of Ionic Block Copolymers, Acc. Chem. Res., 1996, 29(2), 95102, DOI: 10.1021 /ar940080.

13 L. Jia, G. Zhao, W. Shi, N. Coombs, I. Gourevich, G. C. Walker, G. Guerin, I. Manners and M. A. Winnik, A Design Strategy for the Hierarchical Fabrication of Colloidal Hybrid Mesostructures, Nat. Commun., 2014, 5, 3882, DOI: $10.1038 /$ ncomms4882. 
14 J.-T. Sun, C.-Y. Hong and C.-Y. Pan, Recent Advances in RAFT Dispersion Polymerization for Preparation of Block Copolymer Aggregates, Polym. Chem., 2013, 4(4), 873-881, DOI: $10.1039 / \mathrm{C} 2 \mathrm{PY} 20612 \mathrm{~A}$.

15 J. Rieger, Guidelines for the Synthesis of Block Copolymer Particles of Various Morphologies by RAFT Dispersion Polymerization, Macromol. Rapid Commun., 2015, 36(16), 1458-1471, DOI: 10.1002/marc.201500028.

16 M. J. Derry, L. A. Fielding and S. P. Armes, PolymerizationInduced Self-Assembly of Block Copolymer Nanoparticles via RAFT Non-Aqueous Dispersion Polymerization, Prog. Polym. Sci., 2016, 52, 1-18, DOI: 10.1016/ j.progpolymsci.2015.10.002.

17 N. J. Warren and S. P. Armes, Polymerization-Induced SelfAssembly of Block Copolymer Nano-Objects via RAFT Aqueous Dispersion Polymerization, J. Am. Chem. Soc., 2014, 136(29), 10174-10185, DOI: 10.1021/ja502843f.

18 S. L. Canning, G. N. Smith and S. P. Armes, A Critical Appraisal of RAFT-Mediated Polymerization-Induced SelfAssembly, Macromolecules, 2016, 49(6), 1985-2001, DOI: 10.1021/acs.macromol.5b02602.

19 J. Yeow and C. Boyer, Photoinitiated Polymerization-Induced Self-Assembly (Photo-PISA): New Insights and Opportunities, Adv. Sci., 2017, 4(7), 1700137, DOI: 10.1002/ advs.201700137.

20 V. J. Cunningham, A. M. Alswieleh, K. L. Thompson, M. Williams, G. J. Leggett, S. P. Armes and O. M. Musa, Poly(glycerol monomethacrylate)-Poly(benzyl Methacrylate) Diblock Copolymer Nanoparticles via RAFT Emulsion Polymerization: Synthesis, Characterization, and Interfacial Activity, Macromolecules, 2014, 47(16), 5613-5623, DOI: 10.1021/ma501140h.

21 B. Charleux, G. Delaittre, J. Rieger and F. D'Agosto, Polymerization-Induced Self-Assembly: From Soluble Macromolecules to Block Copolymer Nano-Objects in One Step, Macromolecules, 2012, 45(17), 6753-6765, DOI: 10.1021/ma300713f.

22 L. Sun, L. Hong and C. Wang, Facile Fabrication of Water Dispersible Latex Particles with Homogeneous or ChainSegregated Surface from RAFT Polymerization Using a Mixture of Two Macromolecular Chain Transfer Agents, Macromol. Rapid Commun., 2016, 37(8), 691-699, DOI: 10.1002/marc.201600003.

23 J. Rieger, F. Stoffelbach, C. Bui, D. Alaimo, C. Jérôme and B. Charleux, Amphiphilic Poly(ethylene Oxide) Macromolecular RAFT Agent as a Stabilizer and Control Agent in $\mathrm{Ab}$ Initio Batch Emulsion Polymerization, Macromolecules, 2008, 41(12), 4065-4068, DOI: 10.1021/ ma800544v.

24 Z. Qiao, T. Qiu, W. Liu, L. Zhang, J. Tu, L. Guo and X. Li, A "green" Method for Preparing ABCBA Penta-Block Elastomers by Using RAFT Emulsion Polymerization, Polym. Chem., 2017, 8(19), 3013-3021, DOI: 10.1039/C7PY00464H.

25 J. Tan, D. Liu, X. Zhang, C. Huang, J. He, Q. Xu, X. Li and L. Zhang, Facile Preparation of Hybrid Vesicles Loaded with Silica Nanoparticles via Aqueous Photoinitiated
Polymerization-Induced Self-Assembly, RSC Adv., 2017, 7(37), 23114-23121, DOI: 10.1039/C7RA02770B.

26 G. Liu, Q. Qiu, W. Shen and Z. An, Aqueous Dispersion Polymerization of 2-Methoxyethyl Acrylate for the Synthesis of Biocompatible Nanoparticles Using a Hydrophilic RAFT Polymer and a Redox Initiator, Macromolecules, 2011, 44(13), 5237-5245, DOI: 10.1021/ma200984h.

27 W. Zhou, Q. Qu, Y. Xu and Z. An, Aqueous PolymerizationInduced Self-Assembly for the Synthesis of KetoneFunctionalized Nano-Objects with Low Polydispersity, ACS Macro Lett., 2015, 495-499, DOI: 10.1021/ acsmacrolett.5b00225.

28 C. A. Figg, A. Simula, K. A. Gebre, B. S. Tucker, D. M. Haddleton and B. S. Sumerlin, PolymerizationInduced Thermal Self-Assembly (PITSA), Chem. Sci., 2015, 6(2), 1230-1236, DOI: 10.1039/C4SC03334E.

29 N. J. Warren, O. O. Mykhaylyk, D. Mahmood, A. J. Ryan and S. P. Armes, RAFT Aqueous Dispersion Polymerization Yields Poly(ethylene Glycol)-Based Diblock Copolymer NanoObjects with Predictable Single Phase Morphologies, J. Am. Chem. Soc., 2014, 136(3), 1023-1033, DOI: 10.1021/ ja410593n.

30 A. Blanazs, J. Madsen, G. Battaglia, A. J. Ryan and S. P. Armes, Mechanistic Insights for Block Copolymer Morphologies: How Do Worms Form Vesicles?, J. Am. Chem. Soc., 2011, 133(41), 16581-16587, DOI: 10.1021/ ja206301a.

31 W.-M. Wan, C.-Y. Hong and C.-Y. Pan, One-Pot Synthesis of Nanomaterials via RAFT Polymerization Induced SelfAssembly and Morphology Transition, Chem. Commun., 2009, 39, 5883-5885, DOI: 10.1039/B912804B.

32 W.-D. He, X.-L. Sun, W.-M. Wan and C.-Y. Pan, Multiple Morphologies of PAA-B-PSt Assemblies throughout RAFT Dispersion Polymerization of Styrene with PAA Macro-CTA, Macromolecules, 2011, 44(9), 3358-3365, DOI: 10.1021/ ma2000674.

33 W.-J. Zhang, C.-Y. Hong and C.-Y. Pan, Fabrication of Spaced Concentric Vesicles and Polymerizations in RAFT Dispersion Polymerization, Macromolecules, 2014, 47(5), 1664-1671, DOI: $10.1021 / \mathrm{ma} 402497 \mathrm{y}$.

34 J. Tan, C. Huang, D. Liu, X. Li, J. He, Q. Xu and L. Zhang, Polymerization-Induced Self-Assembly of Homopolymer and Diblock Copolymer: A Facile Approach for Preparing Polymer Nano-Objects with Higher-Order Morphologies, ACS Macro Lett., 2017, 6(3), 298-303, DOI: 10.1021/ acsmacrolett.7b00134.

35 J. Tan, D. Liu, C. Huang, X. Li, J. He, Q. Xu and L. Zhang, Photoinitiated Polymerization-Induced Self-Assembly of Glycidyl Methacrylate for the Synthesis of EpoxyFunctionalized Block Copolymer Nano-Objects, Macromol. Rapid Commun., 2017, 38(15), 1700195, DOI: 10.1002/ marc.201700195.

36 E. R. Jones, M. Semsarilar, A. Blanazs and S. P. Armes, Efficient Synthesis of Amine-Functional Diblock Copolymer Nanoparticles via RAFT Dispersion Polymerization of Benzyl Methacrylate in Alcoholic 
Media, Macromolecules, 2012, 45(12), 5091-5098, DOI: 10.1021/ma300898e.

37 M. Semsarilar, E. R. Jones, A. Blanazs and S. P. Armes, Efficient Synthesis of Sterically-Stabilized Nano-Objects via RAFT Dispersion Polymerization of Benzyl Methacrylate in Alcoholic Media, Adv. Mater., 2012, 24(25), 3378-3382, DOI: 10.1002/adma.201200925.

38 D. Zehm, L. P. D. Ratcliffe and S. P. Armes, Synthesis of Diblock Copolymer Nanoparticles via RAFT Alcoholic Dispersion Polymerization: Effect of Block Copolymer Composition, Molecular Weight, Copolymer Concentration, and Solvent Type on the Final Particle Morphology, Macromolecules, 2013, 46(1), 128-139, DOI: 10.1021/ma301459y.

39 E. R. Jones, M. Semsarilar, P. Wyman, M. Boerakker and S. P. Armes, Addition of Water to an Alcoholic RAFT PISA Formulation Leads to Faster Kinetics but Limits the Evolution of Copolymer Morphology, Polym. Chem., 2016, 7(4), 851-859, DOI: 10.1039/C5PY01795E.

40 A. B. Lowe, RAFT Alcoholic Dispersion Polymerization with Polymerization-Induced Self-Assembly, Polymer, 2016, 106, 161-181, DOI: 10.1016/j.polymer.2016.08.082.

41 E. T. Garrett, Y. Pei and A. B. Lowe, Microwave-Assisted Synthesis of Block Copolymer Nanoparticles via RAFT with Polymerization-Induced Self-Assembly in Methanol, Polym. Chem., 2015, 7(2), 297-301, DOI: 10.1039/C5PY01672J.

42 Y. Pei and A. B. Lowe, Polymerization-Induced SelfAssembly: Ethanolic RAFT Dispersion Polymerization of 2-Phenylethyl Methacrylate, Polym. Chem., 2014, 5(7), 23422351, DOI: 10.1039/C3PY01719B.

43 W. Zhou, Q. Qu, W. Yu and Z. An, Single Monomer for Multiple Tasks: Polymerization Induced Self-Assembly, Functionalization and Cross-Linking, and Nanoparticle Loading, ACS Macro Lett., 2014, 3(12), 1220-1224, DOI: 10.1021/mz500650c.

44 Z. Ding, C. Gao, S. Wang, H. Liu and W. Zhang, MacroRAFT Agent Mediated Dispersion Polymerization: The Monomer Concentration Effect on the Morphology of the in Situ Synthesized Block Copolymer Nano-Objects, Polym. Chem., 2015, 6(46), 8003-8011, DOI: 10.1039/ C5PY01202C.

45 C. Gao, S. Li, Q. Li, P. Shi, S. A. Shah and W. Zhang, Dispersion RAFT Polymerization: Comparison between the Monofunctional and Bifunctional Macromolecular RAFT Agents, Polym. Chem., 2014, 5(24), 6957-6966, DOI: 10.1039/C4PY01069H.

46 C. Gao, J. Wu, H. Zhou, Y. Qu, B. Li and W. Zhang, Self-Assembled Blends of AB/BAB Block Copolymers Prepared through Dispersion RAFT Polymerization, Macromolecules, 2016, 49(12), 4490-4500, DOI: 10.1021/ acs.macromol.6b00771.

47 P. Shi, Y. Qu, C. Liu, H. Khan, P. Sun and W. Zhang, RedoxResponsive Multicompartment Vesicles of FerroceneContaining Triblock Terpolymer Exhibiting On-Off Switchable Pores, ACS Macro Lett., 2016, 5(1), 88-93, DOI: 10.1021/acsmacrolett.5b00928.
48 L. A. Fielding, J. A. Lane, M. J. Derry, O. O. Mykhaylyk and S. P. Armes, Thermo-Responsive Diblock Copolymer Worm Gels in Non-Polar Solvents, J. Am. Chem. Soc., 2014, 136(15), 5790-5798, DOI: 10.1021/ja501756h.

49 L. P. D. Ratcliffe, B. E. McKenzie, G. M. D. Le Bouëdec, C. N. Williams, S. L. Brown and S. P. Armes, Polymerization-Induced Self-Assembly of All-Acrylic Diblock Copolymers via RAFT Dispersion Polymerization in Alkanes, Macromolecules, 2015, 48(23), 8594-8607, DOI: 10.1021/acs.macromol.5b02119.

50 Y. Pei, L. Thurairajah, O. R. Sugita and A. B. Lowe, RAFT Dispersion Polymerization in Nonpolar Media: Polymerization of 3-Phenylpropyl Methacrylate in NTetradecane with Poly(stearyl Methacrylate) Homopolymers as Macro Chain Transfer Agents, Macromolecules, 2015, 48(1), 236-244, DOI: 10.1021/ma502230h.

51 C. Gao, H. Zhou, Y. Qu, W. Wang, H. Khan and W. Zhang, Situ Synthesis of Block Copolymer Nanoassemblies via Polymerization-Induced Self-Assembly in Poly(ethylene Glycol), Macromolecules, 2016, 49(10), 3789-3798, DOI: 10.1021/acs.macromol.6b00688.

52 J. Tan, H. Sun, M. Yu, B. S. Sumerlin and L. Zhang, PhotoPISA: Shedding Light on Polymerization-Induced SelfAssembly, ACS Macro Lett., 2015, 4(11), 1249-1253, DOI: 10.1021/acsmacrolett.5b00748.

53 J. Tan, C. Huang, D. Liu, X. Zhang, Y. Bai and L. Zhang, Alcoholic Photoinitiated Polymerization-Induced SelfAssembly (Photo-PISA): A Fast Route toward Poly(isobornyl Acrylate)-Based Diblock Copolymer Nano-Objects, ACS Macro Lett., 2016, 894-899, DOI: 10.1021/ acsmacrolett.6b00439.

54 J. Tan, Y. Bai, X. Zhang and L. Zhang, Room Temperature Synthesis of Poly(poly(ethylene Glycol) Methyl Ether Methacrylate)-Based Diblock Copolymer Nano-Objects via Photoinitiated Polymerization-Induced Self-Assembly (Photo-PISA), Polym. Chem., 2016, 7(13), 2372-2380, DOI: 10.1039/C6PY00022C.

55 J. Tan, Y. Bai, X. Zhang, C. Huang, D. Liu and L. Zhang, LowTemperature Synthesis of Thermoresponsive Diblock Copolymer Nano-Objects via Aqueous Photoinitiated Polymerization-Induced Self-Assembly (Photo-PISA) Using Thermoresponsive Macro-RAFT Agents, Macromol. Rapid Commun., 2016, 37(17), 1434-1440, DOI: 10.1002/ marc.201600299.

56 J. Tan, X. Zhang, D. Liu, Y. Bai, C. Huang, X. Li and L. Zhang, Facile Preparation of CO2-Responsive Polymer Nano-Objects via Aqueous Photoinitiated Polymerization-Induced SelfAssembly (Photo-PISA), Macromol. Rapid Commun., 2017, 38(13), 1600508, DOI: 10.1002/marc.201600508.

57 J. Tan, D. Liu, Y. Bai, C. Huang, X. Li, J. He, Q. Xu, X. Zhang and L. Zhang, An Insight into Aqueous Photoinitiated Polymerization-Induced Self-Assembly (Photo-PISA) for the Preparation of Diblock Copolymer Nano-Objects, Polym. Chem., 2017, 8(8), 1315-1327, DOI: 10.1039/C6PY02135B.

58 J. Yeow, J. Xu and C. Boyer, Polymerization-Induced SelfAssembly Using Visible Light Mediated Photoinduced Electron Transfer-Reversible Addition-Fragmentation 
Chain Transfer Polymerization, ACS Macro Lett., 2015, 4(9), 984-990, DOI: 10.1021/acsmacrolett.5b00523.

59 J. Yeow, O. R. Sugita and C. Boyer, Visible Light-Mediated Polymerization-Induced Self-Assembly in the Absence of External Catalyst or Initiator, ACS Macro Lett., 2016, 5(5), 558-564, DOI: 10.1021/acsmacrolett.6b00235.

60 J. Yeow, S. Shanmugam, N. Corrigan, R. P. Kuchel, J. Xu and C. Boyer, A Polymerization-Induced Self-Assembly Approach to Nanoparticles Loaded with Singlet Oxygen Generators, Macromolecules, 2016, 49(19), 7277-7285, DOI: 10.1021/ acs.macromol.6b01581.

61 Q. Yu, Y. Ding, H. Cao, X. Lu and Y. Cai, Use of Polyion Complexation for Polymerization-Induced Self-Assembly in Water under Visible Light Irradiation at $25{ }^{\circ} \mathrm{C}, A C S$ Macro Lett., 2015, 4(11), 1293-1296, DOI: 10.1021/ acsmacrolett.5b00699.

62 Y. Jiang, N. Xu, J. Han, Q. Yu, L. Guo, P. Gao, X. Lu and Y. Cai, The Direct Synthesis of Interface-Decorated Reactive Block Copolymer Nanoparticles via Polymerisation-Induced SelfAssembly, Polym. Chem., 2015, 6(27), 4955-4965, DOI: 10.1039/C5PY00656B.

63 J. Tan, D. Liu, Y. Bai, C. Huang, X. Li, J. He, Q. Xu and L. Zhang, Enzyme-Assisted Photoinitiated PolymerizationInduced Self-Assembly: An Oxygen-Tolerant Method for Preparing Block Copolymer Nano-Objects in Open Vessels and Multiwell Plates, Macromolecules, 2017, 50(15), 57985806, DOI: 10.1021/acs.macromol.7b01219.

64 G. Ng, J. Yeow, J. Xu and C. Boyer, Application of Oxygen Tolerant PET-RAFT to Polymerization-Induced SelfAssembly, Polym. Chem., 2017, 8(18), 2841-2851, DOI: 10.1039/C7PY00442G.

65 B. Yuan, X. He, Y. Qu, C. Gao, E. Eiser and W. Zhang, Situ Synthesis of a Self-Assembled AB/B Blend of Poly(ethylene Glycol)-B-Polystyrene/Polystyrene by Dispersion RAFT Polymerization, Polym. Chem., 2017, 8(14), 2173-2181, DOI: 10.1039/C7PY00339K.

66 A. Zhu, X. Lv, L. Shen, B. Zhang and Z. An, PolymerizationInduced Cooperative Assembly of Block Copolymer and
Homopolymer via RAFT Dispersion Polymerization, ACS Macro Lett., 2017, 6(3), 304-309, DOI: 10.1021/ acsmacrolett.7b00069.

67 X. He, Y. Qu, C. Gao and W. Zhang, Synthesis of Multicompartment Nanoparticles of a Triblock Terpolymer by Seeded RAFT Polymerization, Polym. Chem., 2015, 6(35), 6386-6393, DOI: 10.1039/C5PY01041A.

68 P. Shi, H. Zhou, C. Gao, S. Wang, P. Sun and W. Zhang, Macro-RAFT Agent Mediated Dispersion Copolymerization: A Small Amount of Solvophilic Co-Monomer Leads to a Great Change, Polym. Chem., 2015, 6(27), 4911-4920, DOI: 10.1039/C5PY00697J.

69 J. T. Lai, D. Filla and R. Shea, Functional Polymers from Novel Carboxyl-Terminated Trithiocarbonates as Highly Efficient RAFT Agents, Macromolecules, 2002, 35(18), 67546756, DOI: $10.1021 / \mathrm{ma} 020362 \mathrm{~m}$.

70 P. Shi, C. Gao, X. He, P. Sun and W. Zhang, Multicompartment Nanoparticles of Poly(4-Vinylpyridine) Graft Block Terpolymer: Synthesis and Application as Scaffold for Efficient $\mathrm{Au}$ Nanocatalyst, Macromolecules, 2015, 48(5), 1380-1389, DOI: 10.1021/ acs.macromol.5b00021.

$71 \mathrm{H}$. Zou, S. Wu and J. Shen, Preparation of Silica-Coated Poly(styrene-Co-4-Vinylpyridine) Particles and Hollow Particles, Langmuir, 2008, 24(18), 10453-10461, DOI: 10.1021/la800366j.

72 D. Dupin, A. Schmid, J. A. Balmer and S. P. Armes, Efficient Synthesis of Poly(2-vinylpyridine)-Silica Colloidal Nanocomposite Particles Using a Cationic Azo Initiator, Langmuir, 2007, 23(23), 11812-11818, DOI: 10.1021/ la701825m.

73 C.-S. Lim, S. I. Seok and S. H. Im, Synthesis of Uniform PS-BP2VP Nanoparticles via Reprecipitation and Their Use as Sacrificial Templates for Inorganic Hollow Nanoparticles, $J$. Mater. Chem., 2012, 22(18), 8772-8774, DOI: 10.1039/ C2JM30497J. 